\title{
molecules
}

ISSN 1420-3049

www.mdpi.com/journal/molecules

Article

\section{Synthesis of Stable and Soluble One-Handed Helical Homopoly(substituted acetylene)s without the Coexistence of Any Other Chiral Moieties via Two-Step Polymer Reactions in Membrane State: Molecular Design of the Starting Monomer}

\author{
Yunosuke Abe ${ }^{1}$, Toshiki Aoki ${ }^{1, *}$, Hongge Jia ${ }^{2}$, Shingo Hadano ${ }^{3}$, Takeshi Namikoshi ${ }^{4}$, \\ Yuriko Kakihana ${ }^{1}$, Lijia Liu ${ }^{1}$, Yu Zang ${ }^{1}$, Masahiro Teraguchi ${ }^{1}$ and Takashi Kaneko ${ }^{1}$ \\ 1 Graduate School of Science and Technology, Niigata University, Ikarashi 2-8050, Nishi-Ku, \\ Niigata 950-2181, Japan \\ 2 Department of Polymeric Material and Engineering, Qiqihar University, Wenhua street 42, \\ Qiqihar 161006, China; E-Mail: jiahongge11@hotmail.com \\ 3 Chemical Resources Laboratory, Tokyo Institute of Technology, 4259 Nagatsuta, Midori-ku, \\ Yokohama 226-8503, Japan; E-Mail: hadano.s.aa@m.titech.ac.jp \\ 4 Material Science and Engineering, Kitami Institute of Technology, 165 Koen-cho, Kitami, \\ Hokkaido 090-8507, Japan; E-Mail: takenami@mail.kitami-it.ac.jp
}

* Author to whom correspondence should be addressed; E-Mail: toshaoki@eng.niigata-u.ac.jp; Tel.: +81-25-262-7280; Fax: +81-25-262-7280.

Received: 15 December 2011; in revised form: 28 December 2011 / Accepted: 30 December 2011 / Published: 4 January 2012

Abstract: A soluble and stable one-handed helical poly(substituted phenylacetylene) without the coexistence of any other chiral moieties was successfully synthesized by asymmetric-induced polymerization of a chiral monomer followed by two-step polymer reactions in membrane state: (1) removing the chiral groups (desubstitution); and (2) introduction of achiral long alkyl groups at the same position as the desubstitution to enhance the solubility of the resulting one-handed helical polymer (resubstitution). The starting chiral monomer should have four characteristic substituents: (i) a chiral group bonded to an easily hydrolyzed spacer group; (ii) two hydroxyl groups; (iii) a long rigid hydrophobic spacer between the chiral group and the polymerizing group; (iv) a long achiral group near the chiral group. As spacer group a carbonate ester was selected. The two hydroxyl groups formed intramolecular hydrogen bonds stabilizing a one-handed helical structure in solution before and after the two-step polymer reactions in membrane 
state. The rigid long hydrophobic spacer, a phenylethynylphenyl group, enhanced the solubility of the starting polymer, and realized effective chiral induction from the chiral side groups to the main chain in the asymmetric-induced polymerization. The long alkyl group near the chiral group avoided shrinkage of the membrane and kept the reactivity of resubstitution in membrane state after removing the chiral groups. The g value $(\mathrm{g}=([\theta] / 3,300) / \varepsilon)$ for the $\mathrm{CD}$ signal assigned to the main chain in the obtained final polymer was almost the same as that of the starting polymer in spite of the absence of any other chiral moieties. Moreover, since the one-handed helical structure was maintained by the intramolecular hydrogen bonds in a solution, direct observation of the one-handed helicity of the final homopolymer has been realized in CD for the solution for the first time.

Keywords: one-handed helicity; chirality; polymer reaction; membrane; phenylacetylene; asymmetric polymerization; solubility

\section{Introduction}

Conjugated polymers like polyacetylenes have aroused interest because of their unique properties such as optical resolution and enantioselective recognition [1-3]. Many kinds of polymers having chiral structures in their main chains and/or pendant groups have been synthesized. Among them, soluble chiral polymers whose chiral structures arise solely from one-handed helical conformations of the conjugated main chains have so far only been synthesized by the helix-sense-selective polymerization (HSSP) of an achiral phenylacetylene monomer by using a chiral catalytic system developed in our laboratory [4-15].

In general, there are two methods to synthesize soluble chiral polymers whose chiral structures are present alone in the main chain as asymmetric carbons and /or as a one-handed helical conformation. One is HSSP [16-19] of an achiral monomer by using a chiral catalyst as a chiral source and the other is asymmetric-induced polymerization (AIP), by using achiral catalysts, of monomers having a chiral group as a chiral source, followed by removing the chiral groups by a polymer reaction of the resulting polymer in solution (AIP-R) [20-29]. However, the examples where the two methods have been applied to synthesize conjugated polymers are very few. In fact, there has been only one example using HSSP reported by our group [4-15] and no examples of the use of AIP-R for obtaining soluble chiral conjugated polymers.

Recently, we have successfully synthesized soluble chiral copoly(substituted phenylacetylene)s whose chiral structures are only in one-handed helical conformations by asymmetric-induced copolymerization of a chiral monomer with an achiral comonomer having a hydrophobic group(AIP) and subsequent desubstitution of the chiral pendant groups from the resulting polymers by one-step polymer reaction in membrane state (RIM; in the case of the same polymer reaction in solution, the one-handed helicity was racemized during the reaction [30]). We also found the efficiency in the asymmetric induction to the main chain in this two-step method (AIP-RIM) was better than that of HSSP. However, the homopolymer by AIP of the chiral monomer was insoluble and therefore chiralities could not be measured directly in $\mathrm{CD}$ for the solutions. 
In this study, a soluble homopolymer having its chirality only in the one-handed helical backbone was synthesized by AIP-RIM (Scheme 1) of a chiral phenylacetylene monomer (1) (Figure 1 and Scheme 2).

Scheme 1. Two-step synthetic route to stable and soluble one-handed helical homo- poly(substituted acetylene)s without the coexistence of any other chiral moieties.
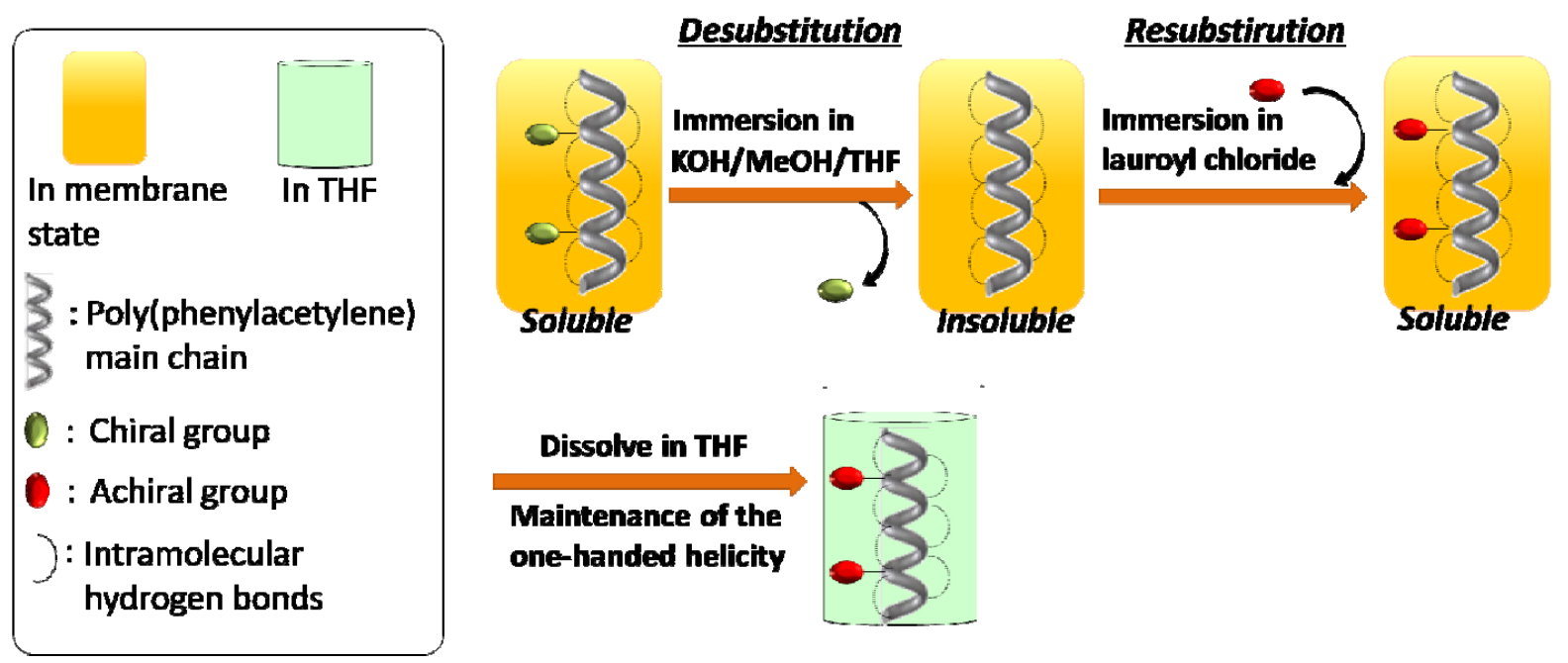

Figure 1. Molecular design of the starting one-handed helical polymer in this study. (1) Removable chiral source by hydrolysis for desubstitution; (2) Stabilization of the one-handed helical backbone by the intramolecular hydrogen bonds; (3) To enhance solubility of the polymer by the hydrophobicity. Effective chiral induction to the backbone from the chiral groups by the rigidity; (4) To enhance reactivity for resubstitution by enhancing the reaction space.

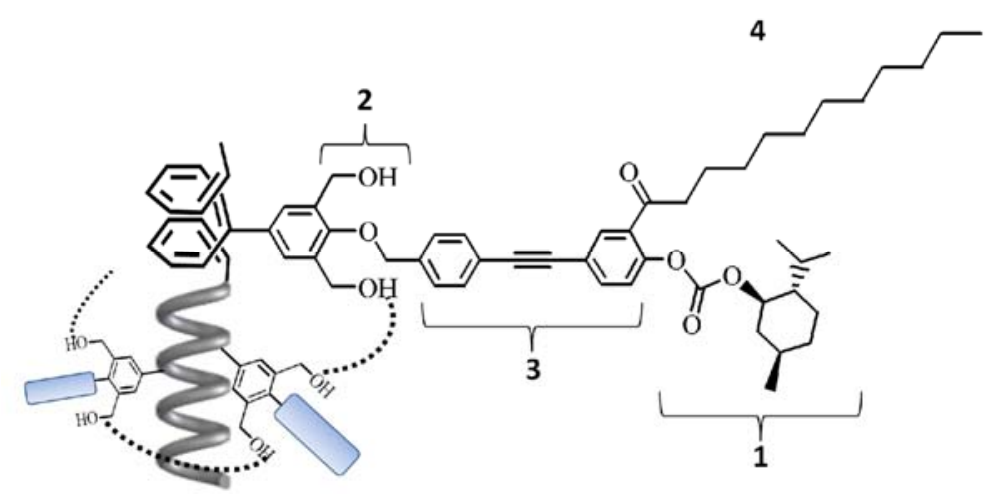

This method consisted of AIP of $\mathbf{1}$ and two-step polymer reactions (desubstitution and resubstitution) in membrane state (RIM): (1) removing the chiral groups while maintaining the one-handed helical backbone (desubstitution); and (2) introduction of achiral long alkyl groups at the same position to enhance solubility of the resulting polymer while maintaining the one-handed helical backbone (resubstitution). As a result, $\mathrm{CD}$ for the resulting polymer could be measured in solution. To realize this purpose, the monomer 1 was designed precisely as follows (Figure 1 and Scheme 2): (i) a chiral group bonded by a group easily hydrolyzed; (ii) two hydroxyl groups to stabilize the one-handed helical backbone of the resulting polymer by the intramolecular hydrogen bonds; 
(iii) a phenylethynylphenyl spacer to enhance the solubility of the polymers, and to realize effective chiral induction from the chiral side group to the main chain in AIP [31]; (iv) a long achiral alkyl group near the chiral group to avoid shrinkage of the polymer membrane and the reactivity of resubstitution in RIM after removing the chiral groups.

Scheme 2. Synthesis of soluble one-handed helical poly(re-1) by asymmetric-induced polymerization followed by polymer reactions in membrane state (AIP-RIM).
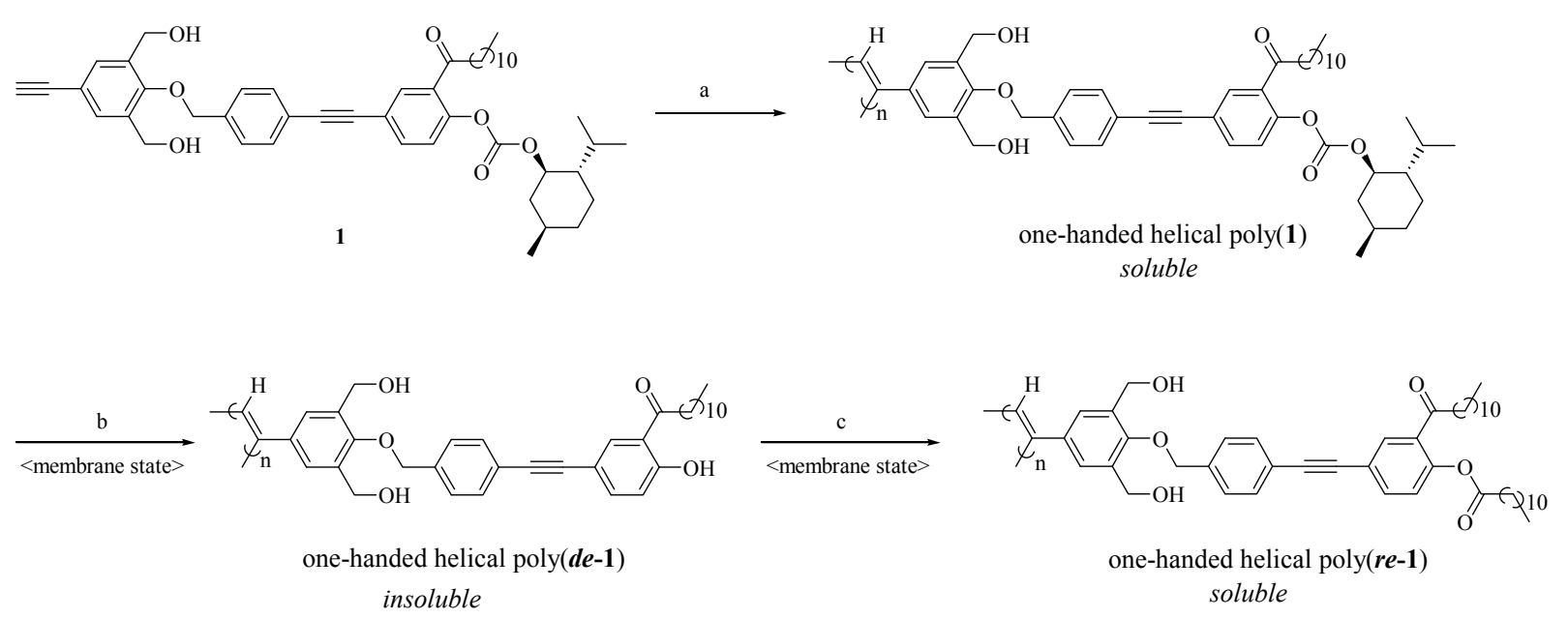

a. $[\mathrm{Rh}(\mathrm{nbd}) \mathrm{Cl}]_{2}, \mathrm{Et}_{3} \mathrm{~N},(\mathbf{A I P}) ;$ b. $\mathrm{KOH} / \mathrm{CH}_{3} \mathrm{OH} / \mathrm{THF}$ in membrane state (RIM); c. lauroyl chloride in membrane state (RIM).

\section{Results and Discussion}

\subsection{Synthesis of a Soluble One-Handed Helical Poly(1) Having Chiral Pendant Groups by} Asymmetric-Induced Polymerization(AIP) of $\mathbf{1}$

By introduction of the hydrophobic phenylethynylphenyl spacer, a soluble poly(1) was successfully synthesized by AIP (Scheme 2 and Table 1) [32]. The value of the specific rotation of poly(1) was much higher than that of the corresponding monomer (Table 1). In addition, since CD signals assigned to the main chain were observed for poly(1), chiral induction to the main chain was confirmed (Figure 2a). In spite of the long distance of the spacer ( $23 \AA$ ), effective chiral induction from the chiral group to the main chain was observed in AIP owing to rigidity of the spacer [31,33]. Moreover, one-handed helicity of poly(1) was stable when it was heated at $60{ }^{\circ} \mathrm{C}$ (Figure 2b). Since the CD and UV spectra for poly(1) (Figure 2a) were very similar to those for a one-handed helical poly(substituted phenylacetylene) (poly(4) in Figure 3) stabilized by intramolecular hydrogen bonds we previously reported [4], the backbone of poly(1) is also thought to be kept by intramolecular hydrogen bonds. When DMSO as a polar solvent was added to the THF solution of poly(1) showing CD around $450 \mathrm{~nm}$ assigned to the main chain (Figure 4a), the CD band disappeared and the UV band shifted to longer wavelengths (Figure $4 \mathrm{~b}$ ). The finding was thought to show that the intramolecular hydrogen bonds were broken, the helical pitch of the conjugated conformation was extended, and then the one-handed helical conformation was racemized. At the same time, a new CD signal assigned to the chiral group in the monomer unit appeared at 250 to $350 \mathrm{~nm}$ (Figure $4 \mathrm{~b}$ ). 
Table 1. Characterizations of $1, \operatorname{poly}(\mathbf{1})^{\mathrm{a}}$ and $\operatorname{poly}(\boldsymbol{r} \boldsymbol{e}-\mathbf{1})$.

\begin{tabular}{cccccc}
\hline Code & $\mathbf{Y i e l d ~}^{\mathbf{b}} / \mathbf{\%}$ & $\boldsymbol{M}_{\mathbf{W}}{ }^{\mathbf{c}} / \times \mathbf{1 0}^{\mathbf{5}}$ & $\boldsymbol{M}_{\mathbf{w}} / \boldsymbol{M}_{\mathbf{n}}{ }^{\mathbf{c}}$ & {$[\boldsymbol{\alpha}]_{\mathbf{D}}{ }^{\mathbf{2 0 d}} /{ }^{\circ}$} & $\mathbf{g}_{\mathbf{4 5 0}}{ }^{\mathbf{e}} / \times \mathbf{1 0} \mathbf{0}^{-\mathbf{7}}$ \\
\hline $\mathbf{1}$ & - & - & - & -18.4 & 0 \\
\hline poly$(\mathbf{1})$ & 98.6 & 27 & 16 & -176 & 2.7 \\
\hline poly $(\boldsymbol{r e}-\mathbf{1})$ & 91.4 & 5.1 & 10 & 117 & 2.5 \\
\hline${ }^{\mathrm{a}}$ At room temperature in toluene, $[\mathbf{1}]$ & $=0.1 \mathrm{~mol} / 1,[\mathbf{1}] /\left[[\mathrm{Rh}(\mathrm{nbd}) \mathrm{Cl}]_{2}\right]=100 ;{ }^{\mathrm{b}}$ methanol insoluble \\
part; $^{\mathrm{c}}$ by GPC; ${ }^{\mathrm{d}}$ in THF; ${ }^{\mathrm{e}} \mathrm{g}=([\theta] / 3300) / \varepsilon$.
\end{tabular}

Figure 2. CD and UV-Vis spectra of poly(1) at (a) $25^{\circ} \mathrm{C}$ and (b) $60{ }^{\circ} \mathrm{C}$ in THF.
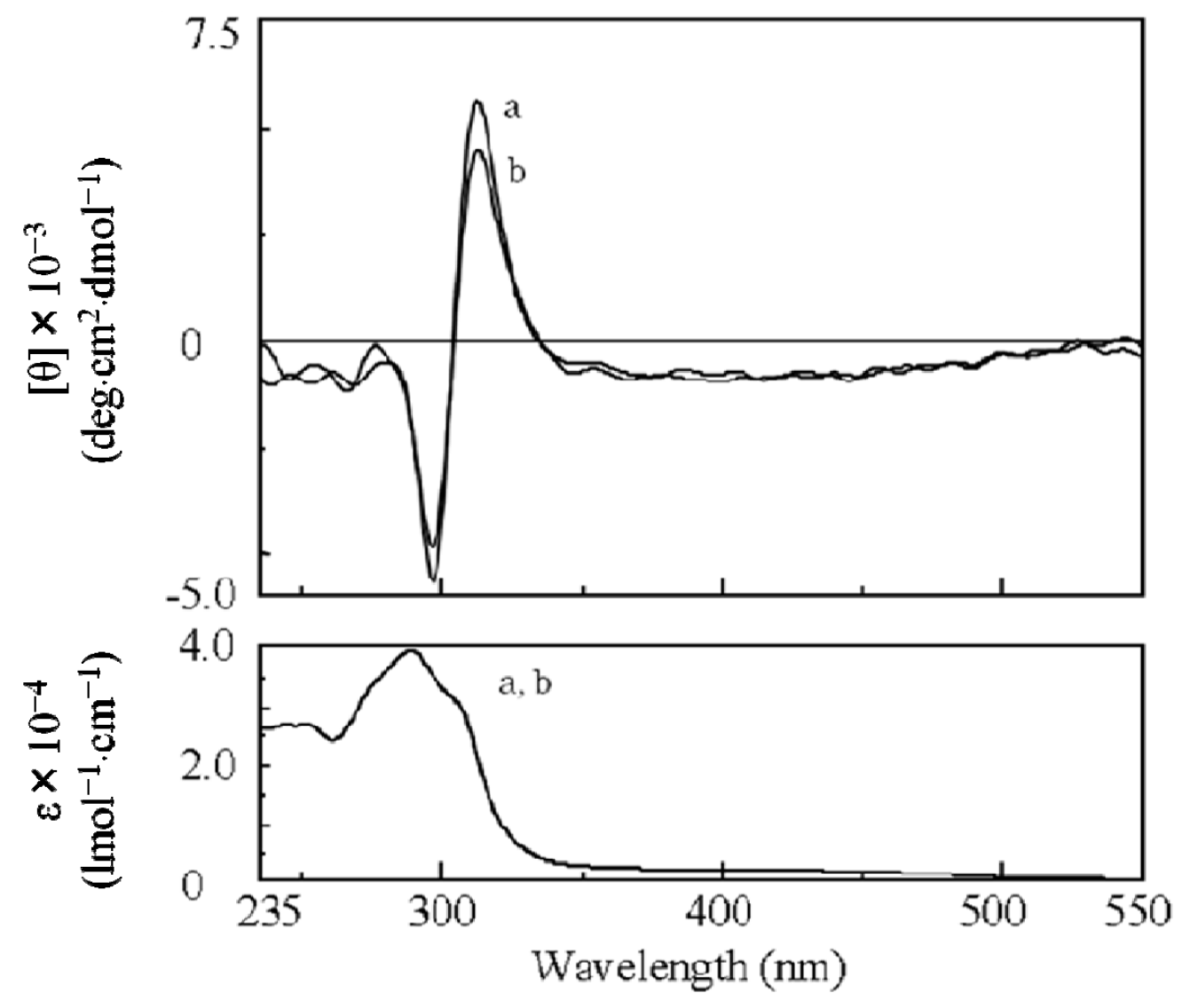

Figure 3. Chemical structures of poly(3) and poly(4).

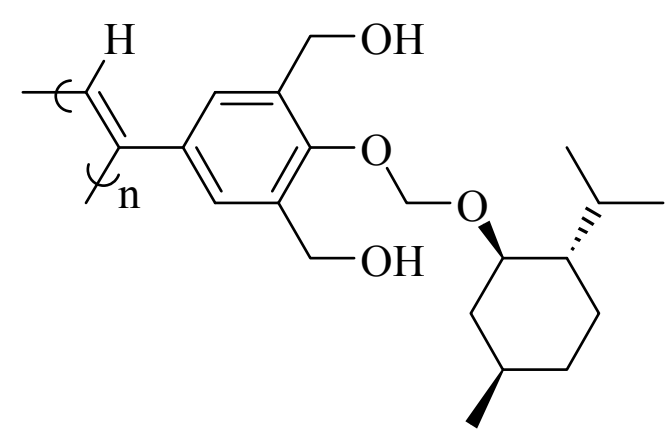

$\operatorname{poly}(3)$

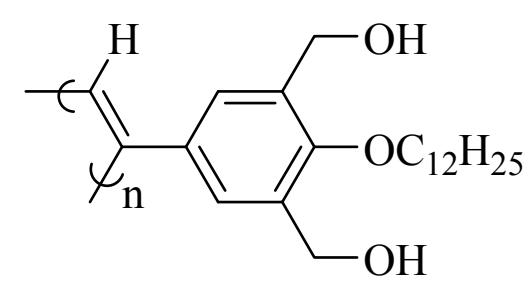

$\operatorname{poly}(4)$ 
Figure 4. CD and UV-Vis spectra of poly(1) in (a) THF, (b) THF/DMSO = 80/20 (v/v) and (c) $\mathrm{THF} / \mathrm{DMSO}=99 / 1(\mathrm{v} / \mathrm{v})((\mathrm{c})$ was the solution prepared by addition of THF to the solution of (b)).

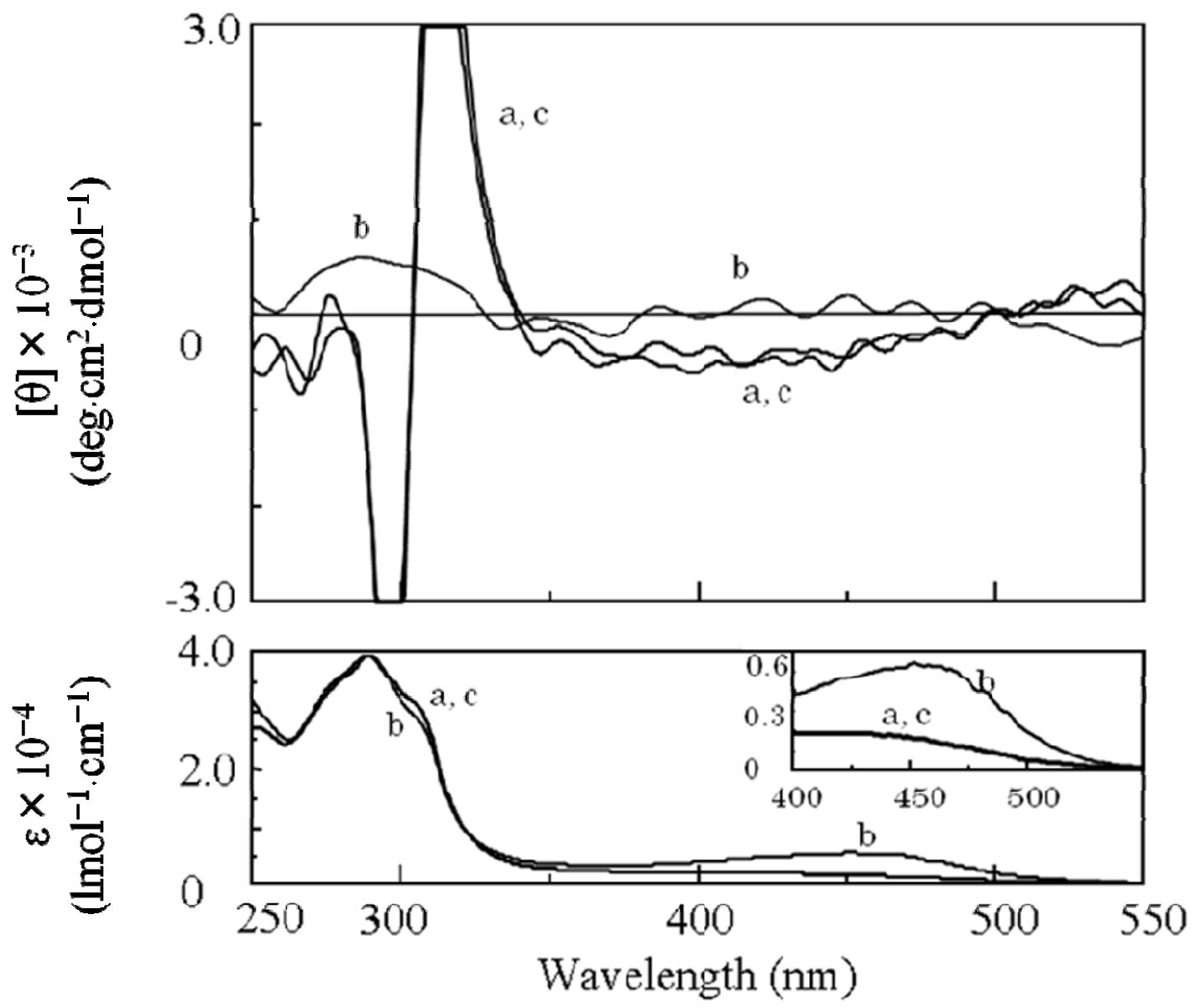

\subsection{Synthesis of an Insoluble One-Handed Helical Poly(de-1) Having no Chiral Pendant Groups by} Removing the Chiral Groups (Desubstitution) Quantitatively from Poly(1) in Membrane State (RIM)

After the desubstitution reaction of the chiral groups from poly(1) in membrane state (RIM), the obtained poly(de-1) became insoluble in any organic solvents. Therefore, the conversion of RIM was estimated by IR and loss of the weight of the membrane. Since the absorption at $1761 \mathrm{~cm}^{-1}$ assigned to the carbonyl stretching vibration in the ester carbonate bonded with the chiral groups completely disappeared (Figures 5a,b) and the actual weight loss was almost the same as the theoretical value (99.7\%), quantitative removal of the chiral groups was confirmed. Because the CD and UV-Vis spectra of poly(de-1) were almost the same as those of poly(1) in membrane state (Figures 6a,b), it was suggested that poly(de-1) maintained the one-handed helical structure of the original polymer in membrane state during RIM. Since the broad absorption band for the hydroxyl groups in poly $(\boldsymbol{d e}-\mathbf{1})$ at 3750 to $3100 \mathrm{~cm}^{-1}$ was observed similar to that in poly(1) (Figures 5a,b), the one-handed helicity may be maintained by the intramolecular hydrogen bonds during the polymer reaction in membrane state. 
Figure 5. IR spectra of (a) poly(1), (b) poly(de-1) and (c) poly(re-1) (film).

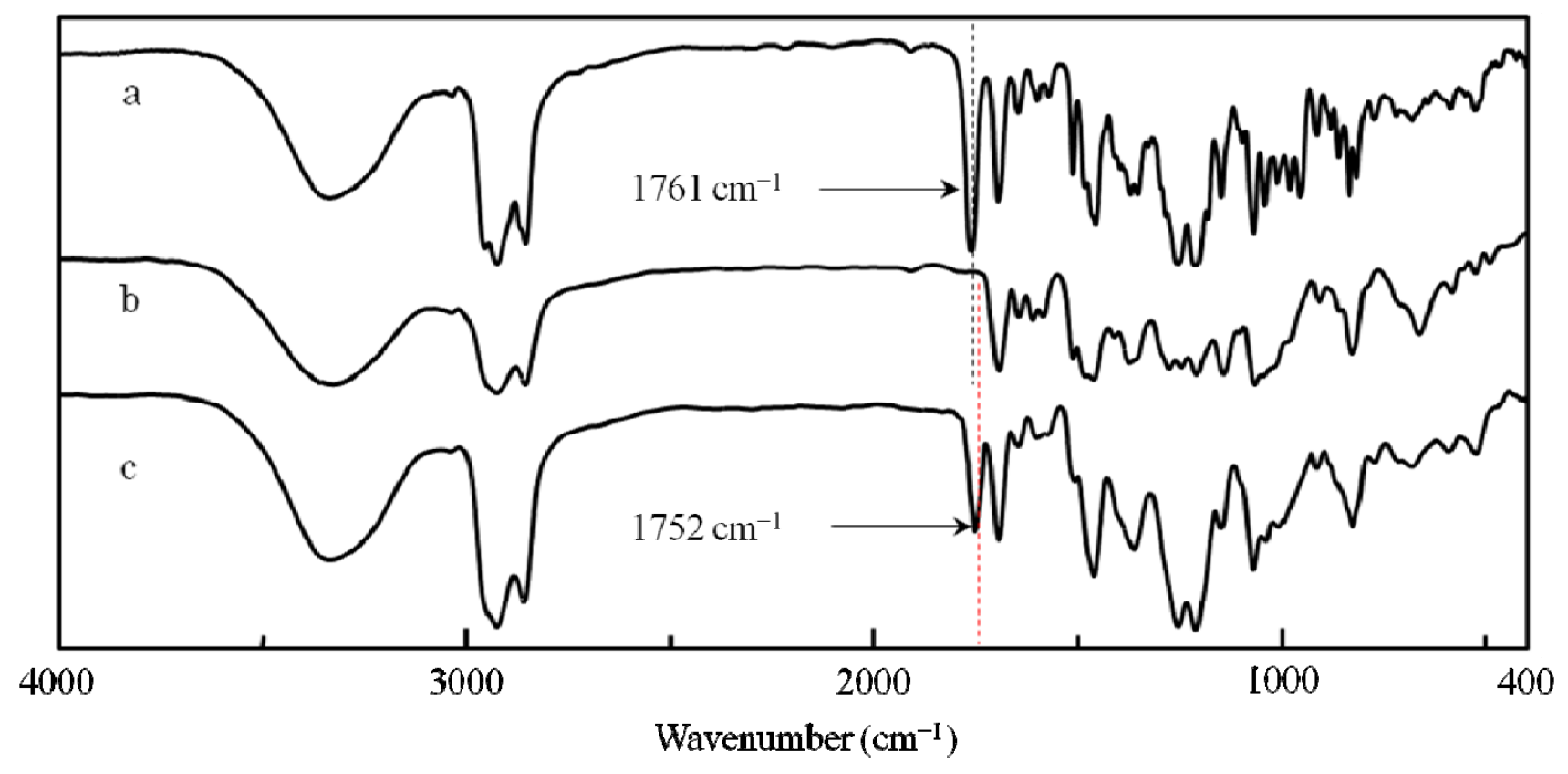

Figure 6. CD and UV-Vis spectra of (a) poly(1), (b) poly(de-1) and (c) poly(re-1) in membrane state.

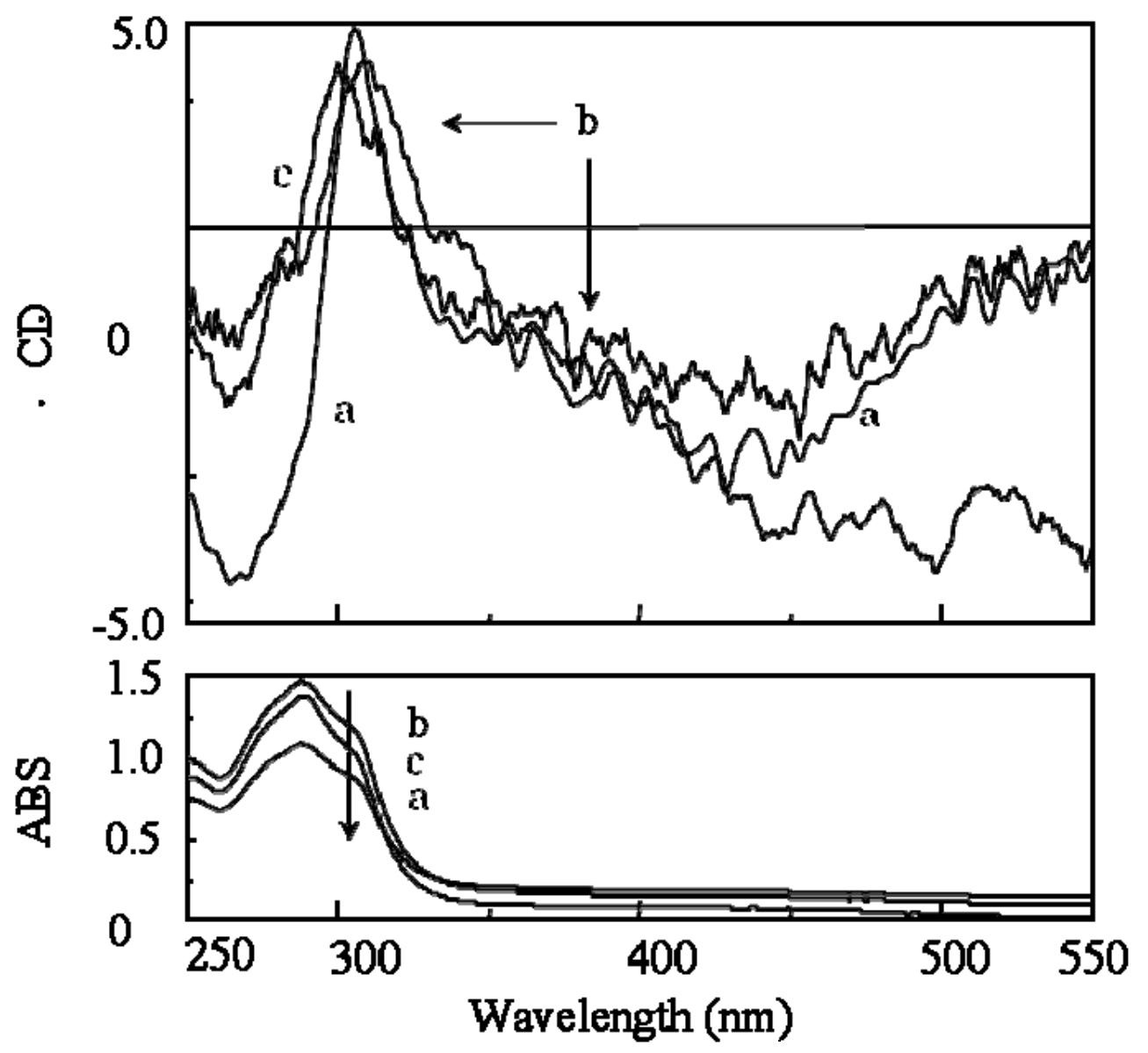




\subsection{Synthesis of a Soluble One-Handed Helical poly(re-1) Having no Chiral Pendant Groups by} Quantitative Introduction of Achiral Groups (Resubstitution) to Poly(de-1) in Membrane State(RIM)

\subsubsection{Quantitative Introduction of Achiral Groups (Resubstitution) by RIM}

After introduction (resubstitution) reaction of the achiral groups by the reaction of phenolic alcohol in poly (de-1) with lauroyl chloride in membrane state (RIM), unlike poly $(\boldsymbol{d e}-\mathbf{1})$ the obtained poly $(\boldsymbol{r e}-\mathbf{1})$ became soluble in chloroform and THF. It was found that the reaction was almost quantitative by IR and ${ }^{1} \mathrm{H}-\mathrm{NMR}$. The ${ }^{1} \mathrm{H}-\mathrm{NMR}$ spectra of $\mathbf{1}$, poly(1) and poly(re-1) are shown in Figure 7 (no data is available for poly(de-1) because of its insolubility). The signals in the chiral menthoxy group of poly(1) observed at 1.48 and $0.94 \mathrm{ppm}$ disappeared completely in poly(re-1), indicating the absence of the chiral groups in poly(re-1). In addition, since the value of the ratio of the integral values of the two methyl protons in the two undecyl groups at 0.87 and $0.81 \mathrm{ppm}$ to the nine aromatic protons assigned to three types of the benzene rings at $7.80-6.73 \mathrm{ppm}$ was the same as theoretical one(6:9), the quantitative de- and re-substitution were confirmed. It was also confirmed by the fact that the absorption at $1752 \mathrm{~cm}^{-1}$ in the IR spectra assigned to the carbonyl stretching vibration of the phenyl ester group newly appeared (Figures 5b,c). Since the broad absorption for the hydroxyl groups in $\operatorname{poly}(\boldsymbol{r e}-\mathbf{1})$ at 3750 to $3100 \mathrm{~cm}^{-1}$ was observed similar to that in poly(1) and poly(de-1) (Figures 5a-c), the one-handed helicity was thought to be maintained by the hydrogen bonds during the polymer reaction in membrane state.

Figure 7. ${ }^{1} \mathrm{H}-\mathrm{NMR}$ spectra of $\mathbf{1}$ in $\mathrm{CDCl}_{3}$ and poly(1) and poly(re-1) in $\mathrm{CDCl}_{3} / \mathrm{DMSO}-d_{6}$.
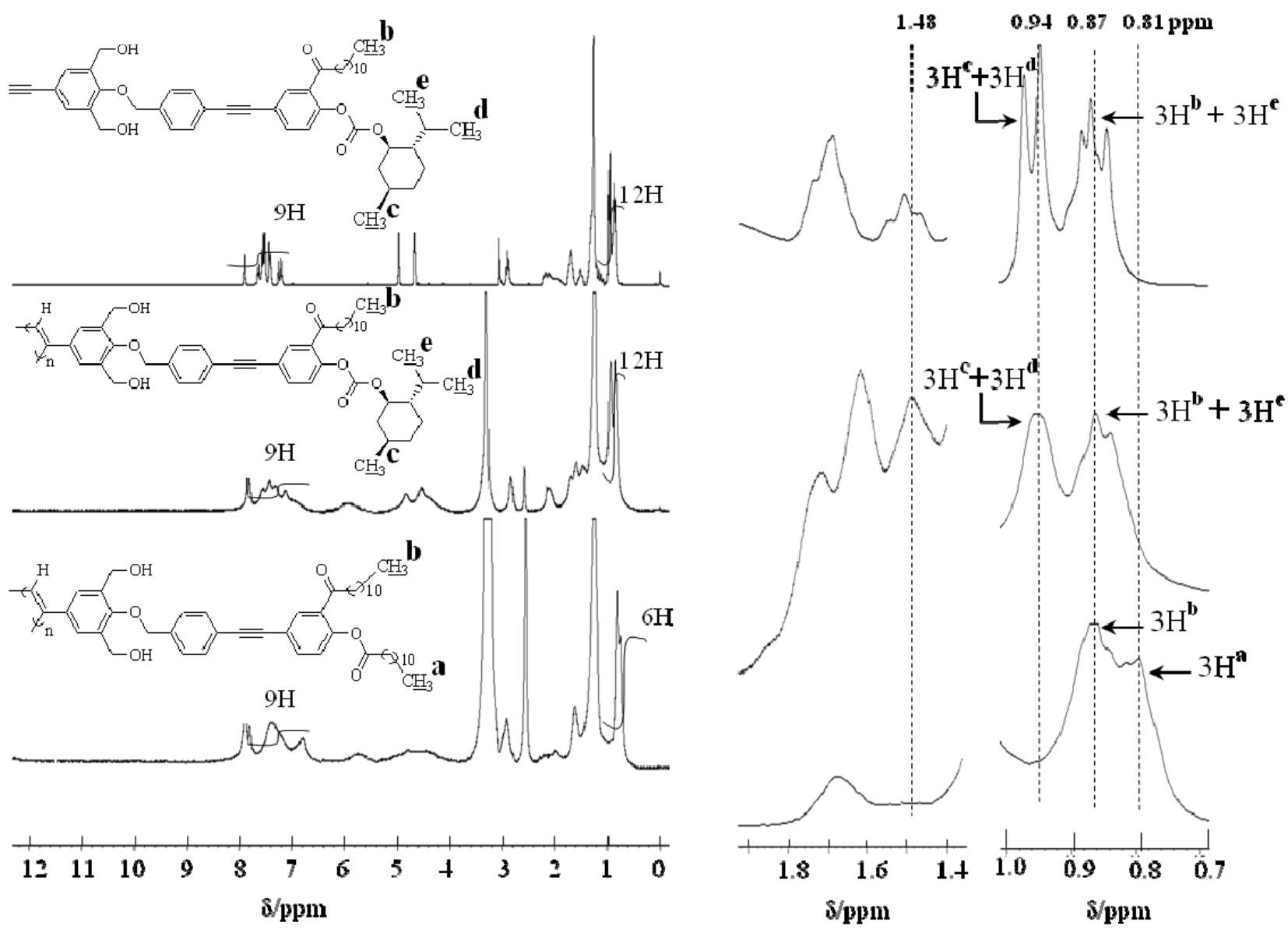
In order to investigate the effect of the long alkyl group near the resubstitution reaction site on the reactivity, a chiral monomer(2) which has no such alkyl groups was synthesized and polymerized as shown in Scheme 3. AIP-RIM of 2 gave poly(de-2), and resubstitution in poly(de-2) membranes was attempted. As a result, the resubstitution did not proceed in poly(de-2) membranes. In the case of the absence of the long alkyl group, shrinkage of the membrane and decrease of the reaction space for resubstitution occurred after removing the bulky menthoxy groups by RIM. In fact, the ratio of decrease $(\%)$ of the diameter from poly(2) to poly(de-2) membranes was $13 \%$ which was larger than that from poly(1) to poly $(\boldsymbol{d e}-\mathbf{1})$ membrane $(4 \%)$. These results indicated that introduction of the long alkyl group near the chiral group reduced shrinkage of the membrane and kept the reactivity of resubstitution in membrane state of poly(de-1) after removing the chiral groups.

Scheme 3. Synthesis of insoluble one-handed helical poly(de-2) by polymer reaction in membrane state(AIP-RIM).
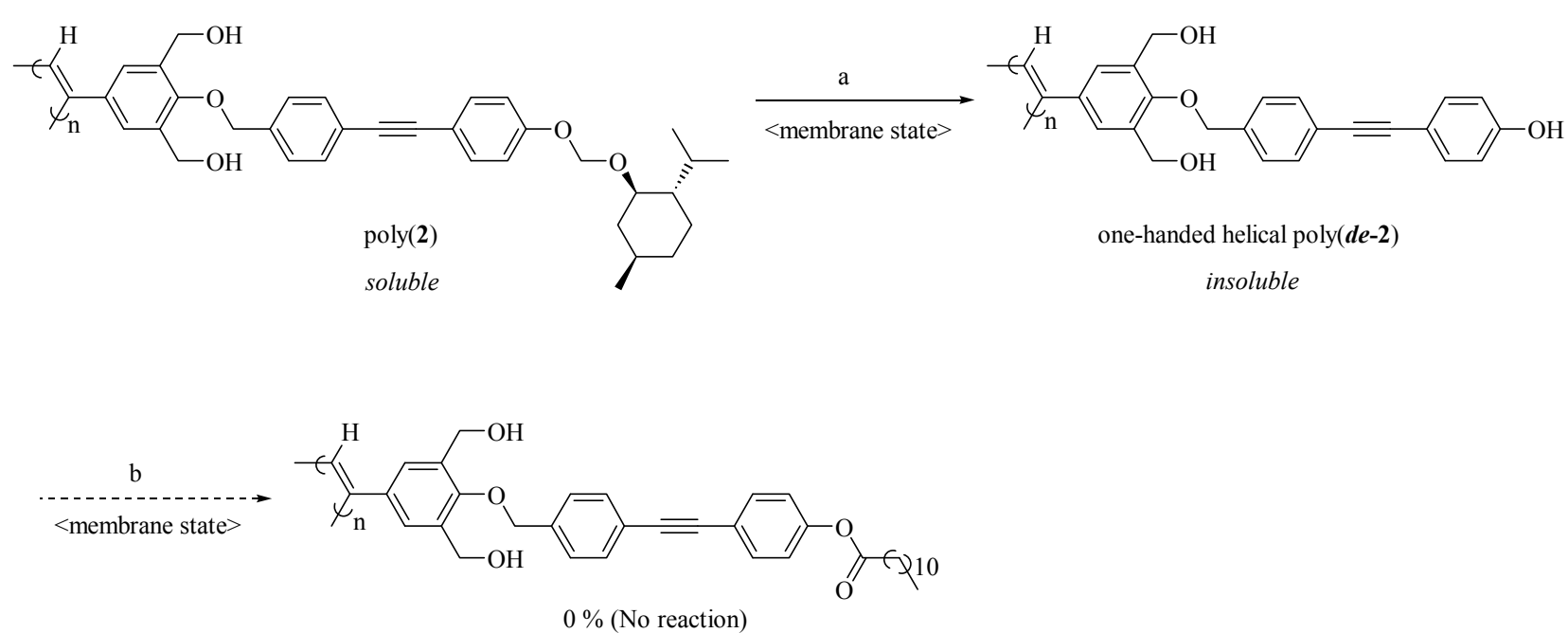

${ }^{\text {a }} 6 \mathrm{~N} \mathrm{HCl} /$ methanol in membrane state (RIM); ${ }^{\mathrm{b}}$ lauroyl chloride in membrane state (RIM).

\subsubsection{Evidence of the One-Handed Helicity of Poly(re-1) Prepared by Two-Step RIM}

Since the obtained soluble poly(re-1) showed CD signals assigned to the main chain in THF (Figure 8), finally by the two-step RIMs we obtained a one-handed helical homopolymer without any other chiral moieties which has the same structure of the backbone as that of poly(4) (Figure 3) prepared only by HSSP of an achiral monomer(4). In addition, the $g$ value $(=([\theta] / 3,300) / \varepsilon)$ of the main chain of poly(re-1) was almost the same as that of the starting polymer, poly(1) (Table 1). Like poly(4), almost no change in the CD intensity of poly(re-1) was observed after heating the solution at $60{ }^{\circ} \mathrm{C}$ (Figure $8 \mathrm{~b}$ ). This may be because the one-handed helical structure was stabilized by the intramolecular hydrogen bonds. When DMSO as a polar solvent was added to the THF solution of poly(re-1) showing CD around $450 \mathrm{~nm}$ assigned to the main chain (Figure 9a), the CD disappeared and the UV band shifted to longer wavelengths in THF/DMSO [80/20(v/v); Figure 9b], because the intramolecular hydrogen bonds were broken, the helical pitch of the conjugated main chain was extended, and the one-handed conformation was racemized similar to those in poly(4). When to the solution of THF/DMSO [80/20(v/v)] where no CD was observed, THF was added to reform 
intramolecular hydrogen bonds, the resulting solution of THF/DMSO (99/1(v/v)) showed no CD signals (Figure 9c) although hydrogen bonds were recovered. It may be because poly(re-1) took a thermodynamically stable racemic helical structure during reconstruction of intramolecular hydrogen bonds due to the absence of the chiral groups in the side chains.

In summary, we obtained soluble and stable one-handed helical homopolymer without any other chiral moieties which had a main-chain structure similar to that of poly(4) previously prepared only by HSSP of an achiral monomer(4). Therefore, AIP followed by the 2-steps RIM (AIP-RIM) method is equivalent to HSSP.

Figure 8. CD and UV-Vis spectra of poly(re-1) at (a) $20^{\circ} \mathrm{C}$ and (b) $60{ }^{\circ} \mathrm{C}$ in THF.

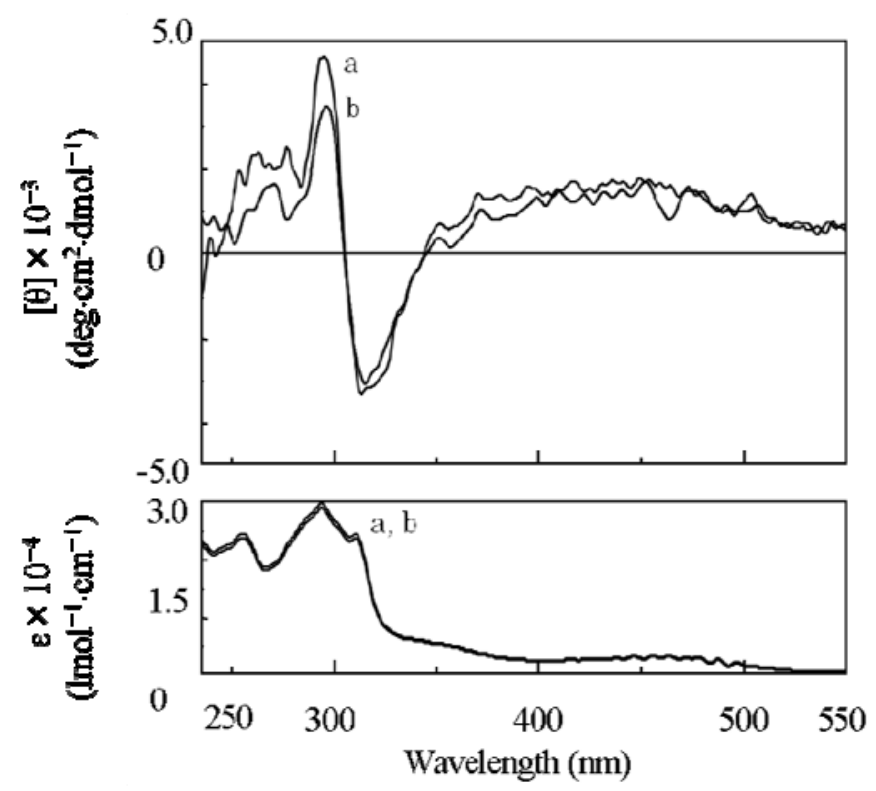

Figure 9. CD and UV-Vis spectra of poly(re-1) in (a) THF, (b) THF/DMSO = 80/20(v/v) and (c) THF/DMSO $=99 / 1(\mathrm{v} / \mathrm{v})((\mathrm{c})$ was the solution prepared by addition of THF to the solution of $b$ ).

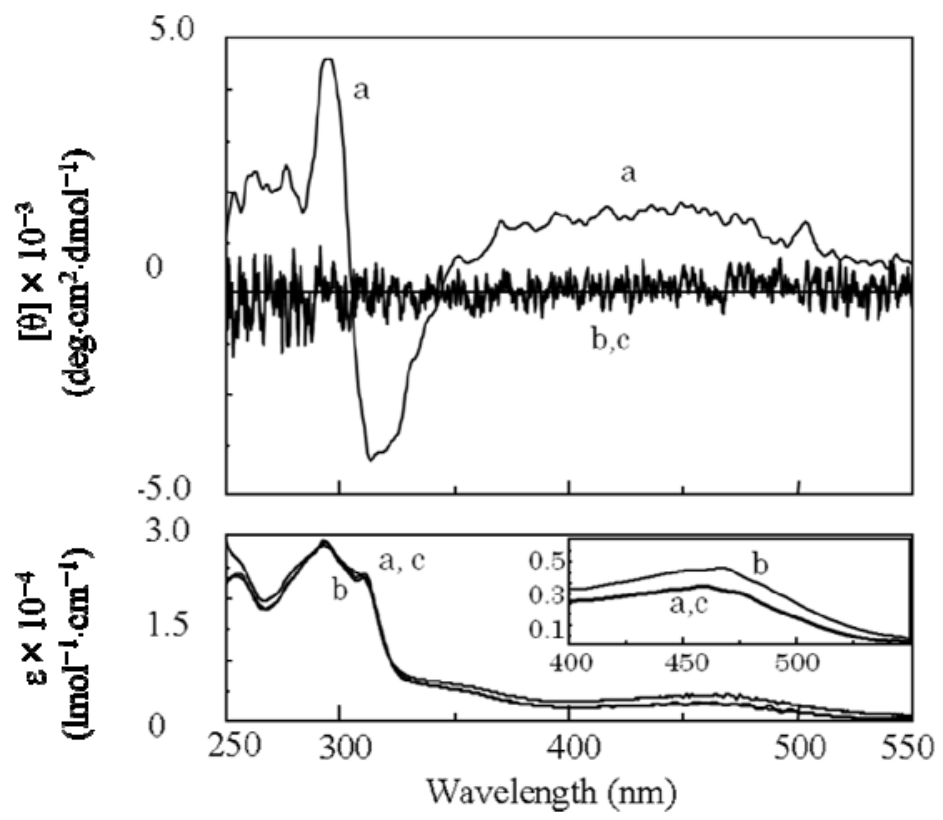




\section{Experimental}

\subsection{General}

All of the solvents used for synthesis and polymerizations of the monomers were distilled as usual. The polymerization initiator, $[\mathrm{Rh}(\mathrm{nbd}) \mathrm{Cl}]_{2}$ (nbd $=2,5$-norbornadiene), purchased from Aldrich Chemical was used as received. Average molecular weights $\left(M_{\mathrm{n}}\right.$ and $\left.M_{\mathrm{w}}\right)$ were estimated by gel permeation chromatography (THF as an eluent, polystyrene calibration) using JASCO Liquid chromatograph instruments with PU-2080, DG-2080-53, CO-2060, UV-2070, CD-2095, and two polystyrene gel columns (Shodex KF-807L). NMR spectra were recorded on a JEOL GSX-270 at 270 $\mathrm{MHz}$ for ${ }^{1} \mathrm{H}$ and $67.5 \mathrm{MHz}$ for ${ }^{13} \mathrm{C}$. IR spectra were recorded on a JASCO FTIR-4200 spectrometer. CD spectra were measured with a JASCO J-720 spectropolarimeter. Specific rotations were recorded with a HORIBA SEPA-200.

\subsection{Monomer Synthesis (see Scheme 4)}

Scheme 4. Synthesis of chiral monomer 1.
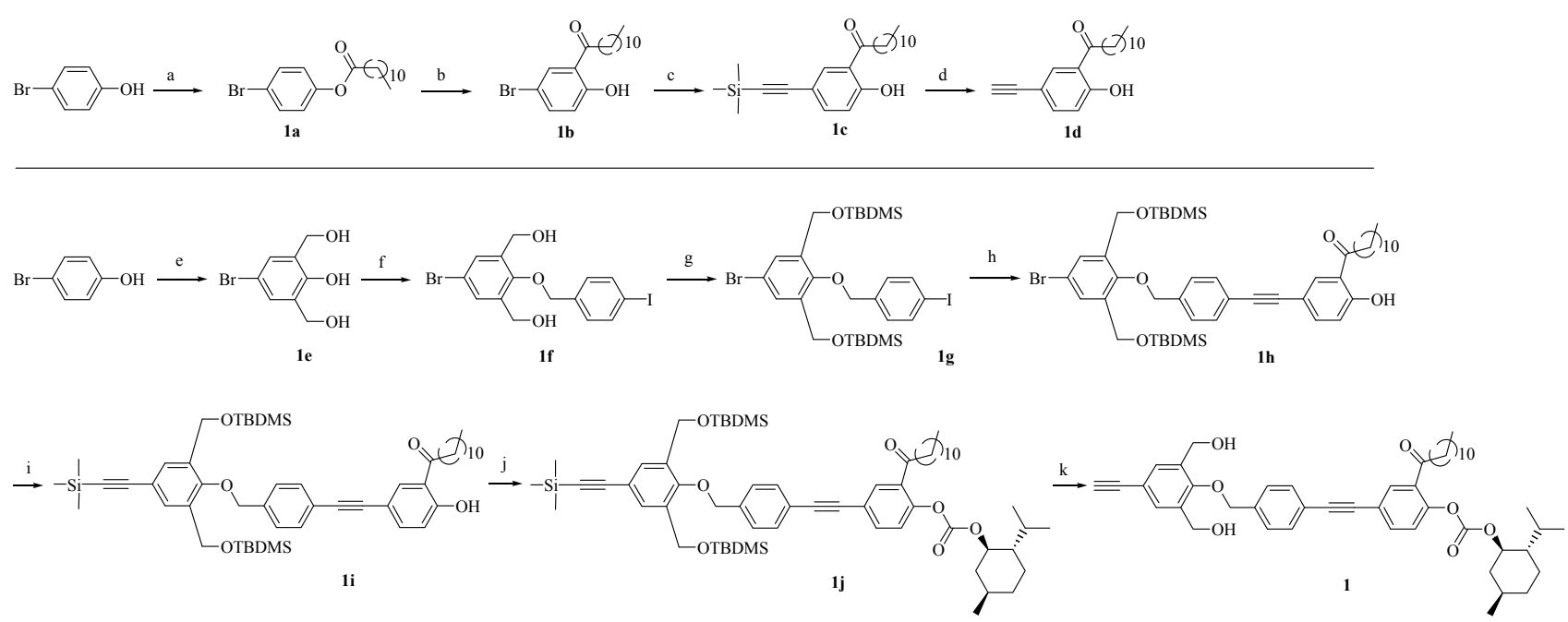

(a) Lauroyl chloride, $60{ }^{\circ} \mathrm{C}$; (b) $\mathrm{AlCl}_{3}, 150{ }^{\circ} \mathrm{C}$; (c) trimethylsilylacetylene, $\mathrm{Pd}\left(\mathrm{PPh}_{3}\right)_{2} \mathrm{Cl}_{2}, \mathrm{CuI}$, $\mathrm{PPh}_{3} / \mathrm{Et}_{3} \mathrm{~N}, 60{ }^{\circ} \mathrm{C}$; (d) $\mathrm{TBAF} / \mathrm{THF}$, r.t.; (e) $\mathrm{HCHO} a q$., $\mathrm{KOH} / 2$-propanol, r.t.; (f) $p$-iodobenzyl bromide, $\mathrm{K}_{2} \mathrm{CO}_{3}$ /acetone, reflux; (g) tert-butyldimethylchlorosilane(TBDMSCl), imidazole/THF, r.t.; (h) 1d, $\mathrm{Pd}\left(\mathrm{PPh}_{3}\right)_{2} \mathrm{Cl}_{2}, \mathrm{CuI}, \mathrm{PPh}_{3} / \mathrm{Et}_{3} \mathrm{~N}$, r.t.; (i) trimethylsilylacetylene, $\mathrm{Pd}\left(\mathrm{PPh}_{3}\right)_{2} \mathrm{Cl}_{2}, \mathrm{CuI}$, $\mathrm{PPh}_{3} / \mathrm{Et}_{3} \mathrm{~N}, 70{ }^{\circ} \mathrm{C}$; (j) (-)-menthyl chloroformate, $\mathrm{Et}_{3} \mathrm{~N} / \mathrm{THF}$, r.t.; (k) TBAF, acetic acid /THF, r.t.

\subsubsection{Synthesis of 4-Bromophenyl dodecanoate (1a)}

In a $500 \mathrm{~mL}$ three-necked flask, $p$-bromophenol $(7.40 \mathrm{~g}, 42.8 \mathrm{mmol})$ was heated at $90{ }^{\circ} \mathrm{C}$. After the p-bromophenol melted, lauroyl chloride $(10.0 \mathrm{~mL}, 43.2 \mathrm{mmol})$ was added. The solution was stirred for $2 \mathrm{~h}$ at $60{ }^{\circ} \mathrm{C}$. After cooling to room temperature, hexane $(200 \mathrm{~mL})$ was added. The solution was washed with aqueous solution of $0.5 \mathrm{wt} \% \mathrm{NaHCO}_{3}$. The organic layer was dried with anhydrous magnesium sulfate. After filtration, the solvent was evaporated and the crude product was purified by recrystallization (hexane) to give 1a as a white solid. Yield: 95.6\% (14.5 g). ${ }^{1} \mathrm{H}-\mathrm{NMR}(270 \mathrm{MHz}$, 
$\left.\mathrm{CDCl}_{3}, \mathrm{ppm}\right) \delta: 7.86(\mathrm{~d}, 2 \mathrm{H}, \mathrm{Br}-\mathrm{Ph} \underline{\mathrm{H}}), 7.68[\mathrm{~d}, 2 \mathrm{H}, \underline{\mathrm{HPhO}}(\mathrm{C}=\mathrm{O})], 2.54\left[\mathrm{t}, 2 \mathrm{H}, \mathrm{PhO}(\mathrm{C}=\mathrm{O}) \mathrm{C}_{2} \mathrm{CH}_{2}\right]$, $1.73\left(\mathrm{~m}, 2 \mathrm{H}, \mathrm{CH}_{2} \mathrm{C}_{2} \mathrm{CH}_{2}\right), 1.27$ [m, 16H, $\left(\mathrm{CH}_{2}\right)_{8}$ in dodecanone group], 0.88 (t, 3H, $\left.\mathrm{CH}_{2} \mathrm{C}_{3}\right)$.

\subsubsection{Synthesis of 5-Bromo-2-hydroxydodecanophenone (1b)}

Anhydrous aluminium chloride $(3.97 \mathrm{~g}, 29.8 \mathrm{mmol})$ was added to $1 \mathrm{a}(7.05 \mathrm{~g}, 19.8 \mathrm{mmol})$ at $110{ }^{\circ} \mathrm{C}$. The resulting mixture was stirred for $2.5 \mathrm{~h}$ at $150{ }^{\circ} \mathrm{C}$. After cooling to room temperature, $1 \mathrm{~N} \mathrm{HCl}$ was added at $0{ }^{\circ} \mathrm{C}$. After extraction with ether, the organic layer was washed with brine and dried with anhydrous magnesium sulfate. After filtration, the solvent was evaporated and the crude product was purified by silica-gel column chromatography (hexane) to give $\mathbf{1 b}$ as a slightly yellow solid. Yield: 15.9\% (1.12 g). Rf: 0.18 (hexane). ${ }^{1} \mathrm{H}-\mathrm{NMR}\left(270 \mathrm{MHz}, \mathrm{CDCl}_{3}, \mathrm{ppm}\right) \delta: 12.3(\mathrm{~s}, 1 \mathrm{H}, \mathrm{PhOH})$, $7.86[\mathrm{~s}, 1 \mathrm{H}, \underline{\mathrm{HPh}}(\mathrm{C}=\mathrm{O})], 7.53(\mathrm{~d}, 1 \mathrm{H}, \mathrm{Br}-\mathrm{Ph} \underline{\mathrm{H}}), 6.83(\mathrm{~d}, 1 \mathrm{H}, \mathrm{HO}-\mathrm{Ph} \underline{\mathrm{H}}), 2.95\left[\mathrm{t}, 2 \mathrm{H}, \mathrm{Ph}(\mathrm{C}=\mathrm{O}) \mathrm{C}_{2} \mathrm{CH}_{2}\right]$, $1.75\left(\mathrm{~m}, 2 \mathrm{H}, \mathrm{CH}_{2} \underline{\mathrm{C}}_{2} \mathrm{CH}_{2}\right), 1.27$ [m, 16H, $\left(\mathrm{CH}_{2}\right)_{8}$ in dodecanone group], $0.88\left(\mathrm{t}, 3 \mathrm{H}, \mathrm{CH}_{2} \underline{\mathrm{C}}_{3}\right)$.

\subsubsection{Synthesis of 2-Hydroxy-5-trimethylsilylethynyldodecanophenone (1c)}

Trimethylsilylacetylene $(0.600 \mathrm{~mL}, 4.22 \mathrm{mmol})$ was added with a syringe to a mixture of $\mathbf{1 b}(1.00 \mathrm{~g}$, $2.84 \mathrm{mmol})$, triphenylphosphine $(59.0 \mathrm{mg}, 0.225 \mathrm{mmol})$, copper iodide $(64.3 \mathrm{mg}, 0.338 \mathrm{mmol})$ and bis(triphenylphosphine)palladium (II) chloride $(39.5 \mathrm{mg}, 56.3 \mu \mathrm{mol})$ in triethylamine $(19 \mathrm{~mL})$. The mixture was stirred at $60{ }^{\circ} \mathrm{C}$ overnight. The formed salt was removed by filtration and the solution was concentrated. After addition of ethyl acetate $(100 \mathrm{~mL})$, the resulting solution was washed with brine. The organic layer was dried with anhydrous magnesium sulfate. After filtration, the solvent was evaporated and the crude product was purified by silica-gel column chromatography (hexane) to give 1c as a slightly viscous liquid. Yield: $86.9 \%$ (991 mg). Rf: 0.10 (hexane). ${ }^{1} \mathrm{H}-\mathrm{NMR}\left(270 \mathrm{MHz}, \mathrm{CDCl}_{3}\right.$, ppm) $\delta: 12.5(\mathrm{~s}, 1 \mathrm{H}, \mathrm{PhO} \underline{\mathrm{H}}), 7.89$ [s, 1H, $\underline{\mathrm{HPh}}(\mathrm{C}=\mathrm{O})], 7.53$ (d, 1H, Si- $\equiv-\mathrm{Ph} \underline{\mathrm{H}}), 6.91(\mathrm{~d}, 1 \mathrm{H}, \mathrm{HO}-\mathrm{Ph} \underline{\mathrm{H}})$, $2.98\left[\mathrm{t}, 2 \mathrm{H}, \mathrm{Ph}(\mathrm{C}=\mathrm{O}) \mathrm{C}_{2} \mathrm{CH}_{2}\right], 1.73\left(\mathrm{~m}, 2 \mathrm{H}, \mathrm{CH}_{2} \mathrm{CH}_{2} \mathrm{CH}_{2}\right), 1.27\left[\mathrm{~m}, 16 \mathrm{H},\left(\mathrm{C}_{2}\right)_{8}\right.$ in dodecanone group], 0.87 (t, $\left.3 \mathrm{H}, \mathrm{CH}_{2} \underline{\mathrm{C}}_{3}\right), 0.26$ [s, $\left.9 \mathrm{H}, \mathrm{Si}\left(\mathrm{C}_{3}\right)_{3}\right]$.

\subsubsection{Synthesis of 5-Ethynyl-2-hydroxydodecanophenone (1d)}

Tetrabutylammonium fluoride $(1 \mathrm{M}$ in THF) $(2.68 \mathrm{~mL}, 2.68 \mathrm{mmol})$ was added to a solution of $1 \mathrm{c}$ (991 mg, $2.44 \mathrm{mmol})$ in THF $(7.1 \mathrm{~mL})$. The solution was stirred at room temperature for $6 \mathrm{~h}$. After addition of ethyl acetate, the solution was washed with brine and dried with anhydrous magnesium sulfate. After filtration, the solvent was evaporated and the crude product was purified by silica-gel column chromatography (hexane-ethyl acetate $=20: 1$ ) to give 1d as a white solid. Yield: $92.7 \%$ (685 mg). Rf: 0.43 (hexane-ethyl acetate = 20:1). IR (KBr): 3700-3000 (OH), $3312(\equiv \mathrm{C}-\mathrm{H}), 3000-2800$ $(\mathrm{CH}), 1690(\mathrm{C}=\mathrm{O}) \mathrm{cm}^{-1} .{ }^{1} \mathrm{H}-\mathrm{NMR}\left(270 \mathrm{MHz}, \mathrm{CDCl}_{3}, \mathrm{ppm}\right) \delta: 12.5(\mathrm{~s}, 1 \mathrm{H}, \mathrm{PhO} \underline{\mathrm{H}}), 7.93[\mathrm{~s}, 1 \mathrm{H}$, $\underline{\mathrm{HPh}}(\mathrm{C}=\mathrm{O})], 7.56(\mathrm{~d}, 1 \mathrm{H}, \equiv \mathrm{Ph} \underline{\mathrm{H}}), 6.95(\mathrm{~d}, 1 \mathrm{H}, \mathrm{HO}-\mathrm{Ph} \underline{\mathrm{H}}), 3.02(\mathrm{~s}, 1 \mathrm{H}, \underline{\mathrm{HC}} \equiv \mathrm{C}), 2.98[\mathrm{t}, 2 \mathrm{H}$, $\left.\mathrm{Ph}(\mathrm{C}=\mathrm{O}) \mathrm{CH}_{2} \mathrm{CH}_{2}\right], 1.74\left(\mathrm{~m}, 2 \mathrm{H}, \mathrm{CH}_{2} \underline{\mathrm{H}}_{2} \mathrm{CH}_{2}\right), 1.27$ [m, 16H, $\left(\mathrm{CH}_{2}\right)_{8}$ in dodecanone group], 0.88 (t, $\left.3 \mathrm{H}, \mathrm{CH}_{2} \underline{\mathrm{CH}}_{3}\right)$.

\subsubsection{Synthesis of 4-Bromo-2,6-bis(hydroxymethyl)phenol (1e)}

Compound 1e was prepared according to our previous method [4]. 


\subsubsection{Synthesis of 1,3-Bis(hydroxymethyl)-2-(4'-iodobenzyloxy)-5-bromobenzene (1f)}

To a solution of $1 \mathrm{e}(4.77 \mathrm{~g}, 20.5 \mathrm{mmol})$ and potassium carbonate $(4.52 \mathrm{~g}, 32.7 \mathrm{mmol})$ in acetone (40 mL), 4-iodobenzyl bromide (7.29 g, $24.5 \mathrm{mmol})$ was added under reflux. The solution was stirred under reflux for $24 \mathrm{~h}$. The formed salt was removed by filtration and the solution was concentrated. After addition of ethyl acetate $(100 \mathrm{~mL})$, the resulting solution was washed with brine. The organic layer was dried with anhydrous magnesium sulfate. After filtration, the solvent was evaporated and the crude product was purified by silica-gel column chromatography (hexane-ethyl acetate $=3: 1$ ) to give 1f as a white solid. Yield: $70.1 \%$ (4.80 g). Rf: 0.33 (hexane-ethyl acetate $=3: 1)$. IR (KBr): 3770-3080 (OH), 3082-2800 (CH) cm ${ }^{-1} .{ }^{1} \mathrm{H}-\mathrm{NMR}\left(270 \mathrm{MHz}, \mathrm{CDCl}_{3}, \mathrm{ppm}\right) \delta: 7.77$ (d, 2H, I-PhH $), 7.47$ (s, 2H, $\mathrm{Br}-\mathrm{Ph} \underline{\mathrm{H}}), 7.25$ (d, 2H, $\left.\mathrm{PhOCH}_{2}-\mathrm{Ph} \underline{\mathrm{H}}\right), 5.27$ (s, 2H, $\left.\mathrm{PhOC}_{2} \mathrm{Ph}\right), 4.80$ [t, 2H, 2( $\left.\left.\mathrm{CH}_{2} \mathrm{O} \underline{\mathrm{H}}\right)\right], 4.50$ [d, 4H, $\left.\left(\mathrm{CH}_{2} \mathrm{OH}\right)\right]$.

\subsubsection{Synthesis of 1,3-Bis(tert-butyldimethylsilyloxymethyl)-2-(4'-iodobenzyloxy)-5-bromobenzene (1g)}

tert-Butyldimethylchlorosilane $(2.21 \mathrm{~g}, 14.7 \mathrm{mmol})$ was added to a solution of $\mathbf{1 f}(3.00 \mathrm{~g}, 6.69 \mathrm{mmol})$ and imidazole $(1.82 \mathrm{~g}, 26.7 \mathrm{mmol})$ in THF $(27 \mathrm{~mL})$ at $0{ }^{\circ} \mathrm{C}$. The solution was stirred for $2 \mathrm{~h}$ at room temperature. After addition of ethyl acetate $(100 \mathrm{~mL})$, the solution was washed with brine. The organic layer was dried with anhydrous sodium sulfate for $12 \mathrm{~h}$. After filtration, the solvent was evaporated and the crude product was purified by silica-gel column chromatography (hexane) to give $\mathbf{1 g}$ as a white solid. Yield: 89.0\% (4.03 g). Rf: 0.53 (hexane-ethyl acetate = 20:1). IR (KBr): 3000-2800 (CH), 1255 (SiC-H), $838(\mathrm{Si}-\mathrm{CH}) \mathrm{cm}^{-1} .{ }^{1} \mathrm{H}-\mathrm{NMR}\left(270 \mathrm{MHz}, \mathrm{CDCl}_{3}, \mathrm{ppm}\right)$ 8: 7.72 (d, 2H, I-Ph프), 7.49

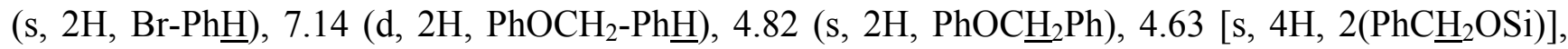
$0.92\left[\mathrm{~s}, 18 \mathrm{H}, 2\left(\mathrm{Si}\left(\mathrm{CH}_{3}\right)_{2} \mathrm{C}\left(\mathrm{C}_{3}\right)_{3}\right)\right], 0.08\left[\mathrm{~s}, 12 \mathrm{H}, 2\left(\mathrm{Si}\left(\mathrm{C}_{\mathrm{H}_{3}}\right)_{2} \mathrm{C}\left(\mathrm{CH}_{3}\right)_{3}\right)\right]$.

3.1.8. Synthesis of 1,3-Bis(tert-butyldimethylsilyloxymethyl)-2-\{4'-[4"-hydroxy-3"-(1-oxododecyl)phenylethynyl]benzyloxy $\}$-5-bromobenzene (1h)

To a mixture of $1 \mathrm{~g}(1.61 \mathrm{~g}, 2.38 \mathrm{mmol})$, triphenylphosphine $(7.13 \mathrm{mg}, 27.2 \mu \mathrm{mol})$, copper iodide (7.76 mg, $40.8 \mu \mathrm{mol}$ ) and bis(triphenylphosphine)palladium (II) chloride (4.77 mg, $6.80 \mu \mathrm{mol})$ in triethylamine $(11.3 \mathrm{~mL})$, 1d $(0.681 \mathrm{mg}, 2.27 \mathrm{mmol})$ was added. The mixture was stirred at room temperature overnight. The formed salt was removed by filtration and the solution was concentrated. After addition of ethyl acetate $(50 \mathrm{~mL})$, the resulting solution was washed with brine. The organic layer was dried with anhydrous magnesium sulfate. After filtration, the solvent was evaporated and the crude product was purified by silica-gel column chromatography (hexane-ethyl acetate $=30: 1$ ) to give 1h as a slightly yellow solid. Yield: $67.7 \%(1.30 \mathrm{~g})$. Rf: 0.40 (hexane-ethyl acetate $=20: 1)$. IR $(\mathrm{KBr})$ : 3700-3100 (OH), 3000-2800 (CH), $1690(\mathrm{C}=\mathrm{O}), 1254(\mathrm{SiC}-\mathrm{H}), 848(\mathrm{Si}-\mathrm{CH}) \mathrm{cm}^{-1}$. ${ }^{1} \mathrm{H}-\mathrm{NMR}(270 \mathrm{MHz}$, $\left.\mathrm{CDCl}_{3}, \mathrm{ppm}\right) \delta: 12.5$ (s, 1H, $\left.\mathrm{PhO} \underline{\mathrm{H}}\right), 7.97[\mathrm{~s}, 1 \mathrm{H}, \underline{\mathrm{HPh}}(\mathrm{C}=\mathrm{O}) \mathrm{C}], 7.63$ [d, 1H, Ph- $\left.=-\mathrm{Ph} \underline{\mathrm{H}}-\mathrm{O}(\mathrm{C}=\mathrm{O})\right], 7.56$

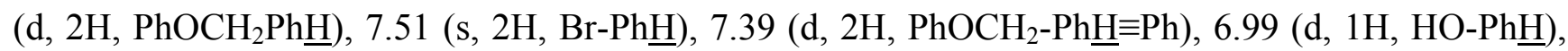
4.89 (s, 2H, PhOC $\left.\underline{H}_{2} \mathrm{Ph}\right), 4.68$ [s, 4H, 2( $\left.\left.\mathrm{PhC}_{2} \mathrm{OSi}\right)\right], 3.02\left[\mathrm{t}, 2 \mathrm{H}, \mathrm{Ph}(\mathrm{C}=\mathrm{O}) \underline{\mathrm{C}}_{2} \mathrm{CH}_{2}\right], 1.77(\mathrm{~m}, 2 \mathrm{H}$, $\left.\mathrm{CH}_{2} \underline{\mathrm{C}}_{2} \mathrm{CH}_{2}\right), 1.27$ [m, 16H, $\left(\mathrm{CH}_{2}\right)_{8}$ in dodecanone group], 0.92 [s, 18H, 2( $\left.\left.\mathrm{Si}\left(\mathrm{CH}_{3}\right)_{2} \mathrm{C}\left(\mathrm{C}_{3}\right)_{3}\right)\right], 0.92$ (t, $\left.3 \mathrm{H}, \mathrm{CH}_{2} \underline{\mathrm{C}}_{3}\right), 0.09\left[\mathrm{~s}, 12 \mathrm{H}, 2\left(\mathrm{Si}\left(\mathrm{C}_{3}\right)_{2} \mathrm{C}\left(\mathrm{CH}_{3}\right)_{3}\right)\right]$. 
3.1.9. Synthesis of 1,3-Bis(tert-butyldimethylsilyloxymethyl)-2-\{4'-[4"-hydroxy-3"-(1-oxododecyl)phenylethynyl]benzyloxy $\}$-5-(trimethylsilylethynyl)benzene (1i)

Trimethylsilylacetylene $(0.342 \mathrm{~mL}, 4.60 \mathrm{mmol})$ was added with a syringe to a mixture of $\mathbf{1 h}(1.30 \mathrm{~g}$, $1.53 \mathrm{mmol})$, triphenylphosphine $(32.1 \mathrm{mg}, 0.122 \mathrm{mmol})$, copper iodide $(35.0 \mathrm{mg}, 0.184 \mathrm{mmol})$ and bis(triphenylphosphine)palladium (II) chloride $(21.5 \mathrm{mg}, 30.6 \mu \mathrm{mol})$ in triethylamine $(10.2 \mathrm{~mL})$. The mixture was stirred at $60^{\circ} \mathrm{C}$ for 2 days. The formed salt was removed by filtration and the solution was concentrated. After addition of ethyl acetate $(100 \mathrm{~mL})$, the resulting solution was washed with brine. The organic layer was dried with anhydrous magnesium sulfate. After filtration, the solvent was evaporated and the crude product was purified by silica-gel column chromatography (hexane-ethyl acetate $=30: 1)$ to give $1 \mathbf{i}$ as a slightly viscous liquid. Yield: $68.1 \%(1.68 \mathrm{~g})$. Rf: 0.39 (hexane-ethyl acetate $=20: 1) . \mathrm{IR}(\mathrm{KBr}): 3700-3000(\mathrm{OH}), 3000-2800(\mathrm{CH}), 1690(\mathrm{C}=\mathrm{O}), 1254(\mathrm{SiC}-\mathrm{H}), 848(\mathrm{Si}-\mathrm{CH})$ $\mathrm{cm}^{-1} .{ }^{1} \mathrm{H}-\mathrm{NMR}\left(270 \mathrm{MHz}, \mathrm{CDCl}_{3}, \mathrm{ppm}\right) \delta: 12.5(\mathrm{~s}, 1 \mathrm{H}, \mathrm{PhO} \underline{\mathrm{H}}), 7.97[\mathrm{~s}, 1 \mathrm{H}, \underline{\mathrm{HPh}}(\mathrm{C}=\mathrm{O}) \mathrm{C}], 7.64$ [d,

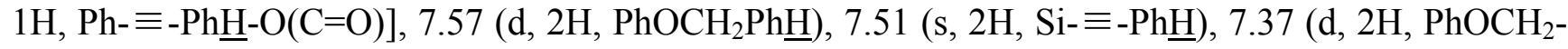

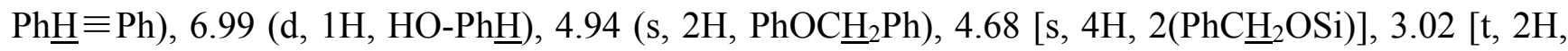
$\mathrm{Ph}(\mathrm{C}=\mathrm{O}) \underline{\mathrm{C}}_{2} \mathrm{CH}_{2}$ ], $1.77\left(\mathrm{~m}, 2 \mathrm{H}, \mathrm{CH}_{2} \mathrm{C}_{2} \mathrm{CH}_{2}\right), 1.27$ [m, 16H, $\left(\mathrm{C}_{2}\right)_{8}$ in dodecanone group], 0.92 [s, 18H, $\left.2\left(\mathrm{Si}\left(\mathrm{CH}_{3}\right)_{2} \mathrm{C}\left(\mathrm{C}_{3}\right)_{3}\right)\right], 0.90$ (t, 3H, $\left.\mathrm{CH}_{2} \mathrm{CH}_{3}\right), 0.25\left[\mathrm{~s}, 9 \mathrm{H}, \equiv-\mathrm{Si}\left(\mathrm{C}_{3}\right)_{3}\right], 0.08$ [s, 12H, 2( $\left.\left.\mathrm{Si}\left(\mathrm{C}_{3}\right)_{2} \mathrm{C}\left(\mathrm{CH}_{3}\right)_{3}\right)\right]$.

3.1.10. Synthesis of 1,3-Bis(tert-butyldimethylsilyloxymethyl)-2-\{4'-[4"-( L-menthoxycarbonyloxy)3"-(1-oxododecyl)phenylethynyl]benzyloxy \}-5-(trimethylsilylethynyl)benzene (1j)

Triethylamine $(41.8 \mu \mathrm{L}, 0.300 \mathrm{mmol})$ was added to a solution of $1 \mathbf{i}(1.68 \mathrm{~g}, 1.94 \mathrm{mmol})$ in THF at room temperature. (-)-menthyl chloroformate $(52.6 \mu \mathrm{L}, 0.248 \mathrm{mmol})$ was added to the solution at room temperature and the solution was stirred for $6 \mathrm{~h}$. After addition of ethyl acetate, the solution was washed with brine and dried with anhydrous sodium sulfate. After filtration, the solvent was evaporated and the crude product was purified by silica-gel column chromatography (hexane-ethyl acetate $=35: 1)$ to give $\mathbf{1} \mathbf{j}$ as a slightly yellow viscous liquid. Yield: $60.3 \%(1.23 \mathrm{~g})$. Rf: 0.37 (hexane:ethyl acetate $=50: 1)$. IR $(\mathrm{KBr}): 3000-2800(\mathrm{CH}), 1758(\mathrm{O}(\mathrm{C}=\mathrm{O}) \mathrm{O}), 1690(\mathrm{C}=\mathrm{O}), 1256(\mathrm{SiC}-\mathrm{H})$, $847(\mathrm{Si}-\mathrm{CH}) \mathrm{cm}^{-1} .{ }^{1} \mathrm{H}-\mathrm{NMR}\left(270 \mathrm{MHz}, \mathrm{CDCl}_{3}, \mathrm{ppm}\right) \delta: 7.90[\mathrm{~s}, 1 \mathrm{H}, \underline{\mathrm{HPh}}(\mathrm{C}=\mathrm{O}) \mathrm{C}], 7.65[\mathrm{~d}, 1 \mathrm{H}, \mathrm{Ph}-\equiv$

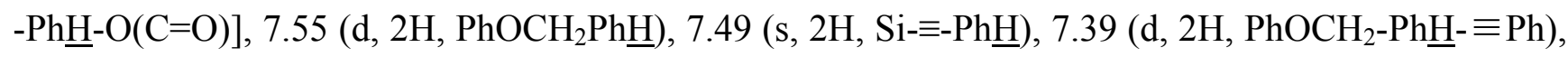
$7.21[\mathrm{~d}, 1 \mathrm{H}, \underline{\mathrm{HPhO}}(\mathrm{C}=\mathrm{O}) \mathrm{O}], 4.89$ (s, 2H, $\left.\mathrm{PhOC} \underline{H}_{2} \mathrm{Ph}\right), 4.68$ [s, 4H, 2( $\left.\left.\mathrm{PhC}_{2} \mathrm{OSi}\right)\right], 4.60-4.50[\mathrm{~m}, 1 \mathrm{H}$, $\mathrm{PhO}(\mathrm{C}=\mathrm{O}) \mathrm{OC} \underline{\mathrm{H}}$, in menthoxy group], $2.90\left[\mathrm{t}, 2 \mathrm{H}, \mathrm{Ph}(\mathrm{C}=\mathrm{O}) \mathrm{C}_{2} \mathrm{CH}_{2}\right], 2.22-2.05(\mathrm{~m}, 2 \mathrm{H}$, methylene, methine in menthoxy group), $1.69\left(\mathrm{~m}, 4 \mathrm{H}, \mathrm{CH}_{2} \underline{\mathrm{CH}}_{2} \mathrm{CH}_{2}\right.$ in dodecanone group and methylene, methine in menthoxy group), 1.51 (m, $2 \mathrm{H}$, methylene in menthoxy group), $1.26\left(\mathrm{~m}, 16 \mathrm{H},\left(\mathrm{C}_{2}\right)_{8}\right.$ in dodecanone group), $1.20-1.02\left(\mathrm{~m}, 3 \mathrm{H}\right.$, methylene, methine in menthoxy group), $0.95\left[\mathrm{~m}, 6 \mathrm{H}, 2\left(\mathrm{CH}_{3} \mathrm{CH}\right)\right.$ in menthoxy group], 0.92 [s, 18H, 2( $\left.\left.\mathrm{Si}\left(\mathrm{CH}_{3}\right)_{2} \mathrm{C}\left(\mathrm{C}_{\mathrm{H}_{3}}\right)_{3}\right)\right], 0.87\left(\mathrm{~m}, 6 \mathrm{H}, \mathrm{CH}_{2} \mathrm{C}_{3}\right.$ in dodecanone and $\mathrm{C}_{3} \mathrm{CH}$ in menthoxy group), $0.26\left[\mathrm{~s}, 9 \mathrm{H}, \equiv-\mathrm{Si}\left(\mathrm{C}_{3}\right)_{3}\right], 0.08$ [s, 12H, 2( $\left.\left.\mathrm{Si}\left(\mathrm{C}_{\mathrm{H}_{3}}\right)_{2} \mathrm{C}\left(\mathrm{CH}_{3}\right)_{3}\right)\right]$.

3.1.11. Synthesis of 3,5-Bis(hydroxymethyl)-4-\{4'-[4"-(L-menthoxycarbonyloxy)-3"-(1-oxododecyl)phenylethynyl]benzyloxy phenylacetylene (1)

A mixture of tetrabutylammonium fluoride $(1 \mathrm{M}$ in THF) $(0.20 \mathrm{~mL}, 0.20 \mathrm{mmol})$ and acetic acid $(0.20 \mathrm{~mL})(=1 / 1(\mathrm{v} / \mathrm{v}))$ was added to a solution of $\mathbf{1} \mathbf{j}(152 \mathrm{mg}, 0.145 \mathrm{mmol})$ in THF $(0.51 \mathrm{~mL})$. The 
solution was stirred at room temperature for $12 \mathrm{~h}$. After addition of ethyl acetate, the solution was washed with brine and dried with anhydrous sodium sulfate. After filtration, the solvent was evaporated and the crude product was purified by silica-gel column chromatography (hexane-ethyl acetate $=3: 1)$ to give 1 as a white solid. Yield: $21.8 \%(49.1 \mathrm{mg})$. Rf: 0.16 (hexane-ethyl acetate = 3:1).

IR (KBr): 3400-3000 (-OH), $3296(\equiv \mathrm{C}-\mathrm{H}), 2954-2854(\mathrm{C}-\mathrm{H}), 1759[\mathrm{O}(\mathrm{C}=\mathrm{O}) \mathrm{O}], 1692(\mathrm{C}=\mathrm{O}) .[\alpha]_{\mathrm{D}}{ }^{20}$ $-18.39^{\circ}(c$ 0.500, THF $) .{ }^{1} \mathrm{H}-\mathrm{NMR}\left(270 \mathrm{MHz}, \mathrm{CDCl}_{3}, \mathrm{ppm}\right) \delta: 7.90[\mathrm{~s}, 1 \mathrm{H}, \underline{\mathrm{HPh}}(\mathrm{C}=\mathrm{O}) \mathrm{C}], 7.64[\mathrm{~d}, 1 \mathrm{H}$,

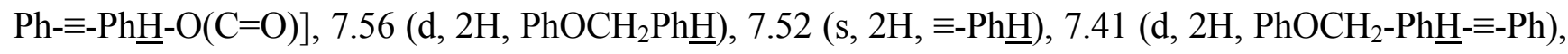
$7.20[\mathrm{~d}, 1 \mathrm{H}, \underline{\mathrm{HPhO}}(\mathrm{C}=\mathrm{O}) \mathrm{O}], 4.97\left(\mathrm{~s}, 2 \mathrm{H}, \mathrm{PhOC} \underline{\mathrm{H}}_{2} \mathrm{Ph}\right), 4.66\left[\mathrm{~s}, 4 \mathrm{H}, 2\left(\mathrm{PhC}_{2} \mathrm{OH}\right)\right], 4.59-4.46[\mathrm{~m}, 1 \mathrm{H}$, $\mathrm{PhO}(\mathrm{C}=\mathrm{O}) \mathrm{OC} \underline{\mathrm{H}}$ in menthoxy group], $3.06(\mathrm{~s}, 1 \mathrm{H}, \underline{\mathrm{HC}} \equiv \mathrm{C}), 2.90\left[\mathrm{t}, 2 \mathrm{H}, \mathrm{Ph}(\mathrm{C}=\mathrm{O}) \mathrm{C}_{2} \mathrm{CH}_{2}\right], 2.21-1.80(\mathrm{~m}$, $2 \mathrm{H}$, methylene, methine, in menthoxy group), $1.70\left(\mathrm{~m}, 4 \mathrm{H}, \mathrm{CH}_{2} \underline{\mathrm{CH}}_{2} \mathrm{CH}_{2}\right.$ in dodecanone group and methylene, methine in menthoxy group), $1.51(\mathrm{~m}, 2 \mathrm{H}$, methylene in menthoxy group), $1.26[\mathrm{~m}, 16 \mathrm{H}$, $\left(\mathrm{CH}_{2}\right)_{8}$ in dodecanone group], 1.19-1.02 (m, 3H, methylene, methine in menthoxy group), 0.94 [br, $6 \mathrm{H}$, $2\left(\underline{\mathrm{H}}_{3} \mathrm{CH}\right)$ in menthoxy group], $0.87\left(\mathrm{~m}, 6 \mathrm{H}, \mathrm{CH}_{2} \underline{\mathrm{C}}_{3}\right.$ in dodecanone and $\mathrm{C}_{3} \mathrm{CH}$ in menthoxy group). ${ }^{13} \mathrm{C}-\mathrm{NMR}\left(\mathrm{CDCl}_{3}, \mathrm{ppm}\right) \delta: 199.5(\mathrm{C}=\mathrm{O}), 154.9(\mathrm{Ph}), 152.5(\mathrm{Ph}), 148.7(\mathrm{C}=\mathrm{O}), 136.9(\mathrm{Ph}), 135.5(\mathrm{Ph})$, $134.5(\mathrm{Ph}), 132.8(\mathrm{Ph}), 132.6(\mathrm{Ph}), 131.9(\mathrm{Ph}), 131.4(\mathrm{Ph}), 127.9(\mathrm{Ph}), 123.5(\mathrm{Ph}), 122.8(\mathrm{Ph}), 121.3$ $(\mathrm{Ph}), 118.6(\mathrm{Ph}), 90.0(\mathrm{C} \equiv \mathrm{C}), 88.2(\mathrm{C} \equiv \mathrm{C}), 83.0(\mathrm{C} \equiv \mathrm{C}), 80.2(\mathrm{C} \equiv \mathrm{C}), 77.2\left(\underline{\mathrm{C}}_{2} \mathrm{OPh}\right), 76.5[\mathrm{O}-\underline{\mathrm{C}} \mathrm{H}(\mathrm{C}-)$ (C-)], 60.5 (-C-OH), 34.1, 29.7, 29.5, 29.6, 29.4, 29.3, 26.2, 22.8, 14.2 (dodecanone group), 47.0, 40.6, 34.1, 32.0, 26.2, 23.4, 22.0, 20.8, 16.4 (menthoxy group). Anal. Calcd for $\mathrm{C}_{48} \mathrm{H}_{60} \mathrm{O}_{7}$ : C, 76.97; H, 8.07. Found. C, 76.87; H, 7.92 .

\subsection{Asymmetric-Induced Polymerization (AIP) and Polymer Reaction in Membrane State (RIM)} (see Schemes 1 and 2)

\subsubsection{Asymmetric-Induced Polymerization (AIP) of 1}

A solution of triethylamine $(34.5 \mu \mathrm{L}, 0.248 \mathrm{mmol})$ and $[\mathrm{Rh}(\mathrm{nbd}) \mathrm{Cl}]_{2}(0.572 \mathrm{mg}, 1.24 \mu \mathrm{mol})$ in toluene $(0.263 \mathrm{~mL})$ was added with a syringe to a solution of $1(92.9 \mathrm{mg}, 0.124 \mathrm{mmol})$ in toluene $(0.265 \mathrm{~mL})$. After the solution was stirred at room temperature for $6 \mathrm{~h}$, the solution was diluted with toluene $(30 \mathrm{~mL})$. The solution was poured into a large amount of methanol to precipitate a red solid, which was filtered out and dried in vacuo. poly(1): Yield $98.6 \%(91.6 \mathrm{mg}) .[\alpha]_{\mathrm{D}}{ }^{20}-176^{\circ}(c 0.100$, THF). IR (film): 3750-3100 (-OH), 2954-2854 (C-H), 1761 [O(C=O)O], $1696(\mathrm{C}=\mathrm{O}) .{ }^{1} \mathrm{H}-\mathrm{NMR}(270 \mathrm{MHz}$, $\left.\mathrm{CDCl}_{3}, \mathrm{ppm}\right) \delta$ : 7.80-7.11 (br, 9H, $\mathrm{Ph} \underline{\mathrm{H}}$ ), 5.91 (br, 0.7H, $\mathrm{CH}_{2}=\mathrm{C} \underline{\mathrm{H}}$ ), 4.83 (br, $\left.2 \mathrm{H}, \mathrm{PhOC} \underline{H}_{2} \mathrm{Ph}\right), 4.55$ [br, 5H, $2\left(\mathrm{PhCH}_{2} \mathrm{OH}\right)$ and $\mathrm{PhO}(\mathrm{C}=\mathrm{O}) \mathrm{OC} \underline{\mathrm{H}}$ in menthoxy group], 2.82 [br, $2 \mathrm{H}, \mathrm{Ph}(\mathrm{C}=\mathrm{O}) \mathrm{CH}_{2} \mathrm{CH}_{2}$ ], 2.13 (br, $2 \mathrm{H}$, methylene, methine in menthoxy group), 1.72 (br, $2 \mathrm{H}, \mathrm{CH}_{2} \underline{\mathrm{C}}_{2} \mathrm{CH}_{2}$ ), 1.62 (br, $2 \mathrm{H}$, methylene, methine in menthoxy group), 1.48 (br, $2 \mathrm{H}$, methylene in menthoxy group), 1.25 [br, $16 \mathrm{H},\left(\mathrm{C}_{2}\right)_{8}$ in dodecanone group], 1.20-1.00 (br, $3 \mathrm{H}$, methylene, methine in menthoxy group), 0.94 [br, $6 \mathrm{H}, 2\left(\mathrm{CH}_{3} \mathrm{CH}\right)$ in menthoxy group], 0.87 (br, $6 \mathrm{H}, \mathrm{CH}_{2} \underline{\mathrm{CH}}_{3}$, in dodecanone group and $\underline{\mathrm{CH}}_{3} \mathrm{CH}$ in menthoxy group).

3.2.2. Synthesis of Poly(de-1) by Desubstitution of the Chiral Groups from Poly(1) in Membrane State (RIM)

A solution of poly $(\mathbf{1})$ in chloroform $((1.5 \mathrm{ml}, 30 \mathrm{mg} / \mathrm{mL})$ was cast on a poly(tetrafluoroethylene) sheet $\left(40 \mathrm{~cm}^{2}\right)$, and the solvent was evaporated for $24 \mathrm{~h}$ at room temperature. The resulting 
free-standing membrane was detached from the sheet and dried in vacuo for $24 \mathrm{~h}$. The membrane was immersed in a solution of potassium hydroxide in THF/methanol (volume ratio 1/3) to desubstitute the chiral groups at room temperature for $36 \mathrm{~h}$. After the reaction, the membrane was washed with methanol and then to neutralize it was immersed in a mixture of methanol/acetic acid (volume ratio 4/1) at room temperature for $1 \mathrm{~h}$. The membrane was immersed in methanol at room temperature overnight to remove the chiral groups remained. After washing the membrane with methanol, the membrane was dried in vacuo overnight. poly(de-1): The weight loss (\%), calcd: 24.28, found: 24.21. IR (film): 3750-3100 (-OH), 2925-2855 (C-H), 1693 (C=O).

\subsubsection{Synthesis of Poly(re-1) by Resubstitution of the Achiral Groups to poly $(\boldsymbol{d e}-\mathbf{1})$ in Membrane State (RIM)}

The membrane of poly $\left(\boldsymbol{d e}\right.$-1) was immersed in lauroyl chloride at $60{ }^{\circ} \mathrm{C}$ for $30 \mathrm{~min}$. After the reaction, the membrane was washed with water, methanol and then hexane. The membrane was immersed in methanol for $6 \mathrm{~h}$ to remove the chiral groups remained. After immersing the membrane in

hexane overnight, the resulting membrane was dried in vacuo for $24 \mathrm{~h}$. poly $(\boldsymbol{r e}-\mathbf{1})$ : Yield $91.4 \%$. $[\alpha]_{\mathrm{D}}{ }^{20}$ $117^{\circ}$ (c 0.100, THF). IR (film): 3750-3100 (-OH), 2926-2857 (C-H), 1752 [O(C=O)], $1694(\mathrm{C}=\mathrm{O})$. ${ }^{1} \mathrm{H}-\mathrm{NMR}\left(270 \mathrm{MHz}, \mathrm{CDCl}_{3}, \mathrm{ppm}\right) \delta: 7.80-6.73$ (br, 9H, $\left.\mathrm{Ph} \underline{\mathrm{H}}\right), 5.83$ (br, 0.6H, $\mathrm{CH}_{2}=\mathrm{C} \underline{\mathrm{H}}$ ), 4.87 [br, 6H, 2( $\left.\mathrm{PhC} \underline{H}_{2} \mathrm{OH}\right)$ and $\mathrm{PhOC} \underline{H}_{2} \mathrm{Ph}$,)], $2.85\left[\mathrm{br}, 2 \mathrm{H}, \mathrm{Ph}(\mathrm{C}=\mathrm{O}) \underline{\mathrm{C}}_{2} \mathrm{CH}_{2}\right], 2.34$ [br, $2 \mathrm{H}, \mathrm{PhO}(\mathrm{C}=\mathrm{O}) \underline{\mathrm{C}}_{2} \mathrm{CH}_{2}$ ], 1.68 [br, 4H, 2( $\left.\mathrm{CH}_{2} \underline{\mathrm{CH}}_{2} \mathrm{CH}_{2}\right)$ in dodecanone groups], 1.24-1.13 [br, 32H, 2( $\left.\mathrm{CH}_{2}\right)_{8}$ in dodecanone groups], 0.87 [br, $\left.3 \mathrm{H}, \mathrm{Ph}(\mathrm{C}=\mathrm{O})\left(\mathrm{CH}_{2}\right)_{10} \mathrm{CH}_{3}\right], 0.81$ [br, $3 \mathrm{H}, \mathrm{PhO}(\mathrm{C}=\mathrm{O})\left(\mathrm{CH}_{2}\right)_{10} \mathrm{C}_{3}$ ].

\subsubsection{Synthesis of Poly(de-2) by Removing the Chiral Groups from Poly(2) in Membrane State (RIM)} (Scheme 3)

According to a procedure similar to that in 3.2.1 and 3.2.2, poly(2) and its membrane were prepared. The membrane was immersed in methanol/2N hydrochloric acid (volume ratio $1 / 1$ ) at $0{ }^{\circ} \mathrm{C}$ for 3 days. It was neutralized in $28 \mathrm{wt} \%$ aqueous ammonia for $12 \mathrm{~h}$, washed with methanol, and dried in vacuo for 24 h. poly(de-2): The weight loss (\%), calcd: 29.69, found: 29.58. IR (film): 3750-3100 (-OH), 2950$2855(\mathrm{C}-\mathrm{H})$.

\section{Conclusions}

A soluble and stable one-handed helical poly(substituted phenylacetylene) without the coexistence of any other chiral moieties was successfully synthesized by AIP of a chiral monomer having a chiral group, followed by two-step RIMs of the resulting polymer: removing the chiral groups (desubstitution), and introduction of achiral long alkyl groups at the same position to enhance the solubility of the resulting one-handed helical polymer (resubstitution). There were two possible reasons for the success: (1) the one-handed helical main chain was maintained because the two polymer reactions were carried out in membrane state; and (2) the polymer's solubilities were maintained by introduction of the two suitable hydrophobic groups to proper positions in the starting monomer. The one-handed helical main chain was kept due to stabilization by intramolecular 
hydrogen bonds. Moreover, the difference in $g$ values between the starting and the final polymer was small.

\section{Acknowledgements}

Partial financial support through a Grant-in-Aid for Scientific Research in a Priority Area "SuperHierarchical Structures" (No. 18039011 and 19022009) from the Ministry of Education, Culture, Sports, Science and Technology, Japan is gratefully acknowledged.

\section{References and Notes}

1. Aoki, T.; Kaneko, T.; Teraguchi, M. Synthesis of functional $\pi$-conjugated polymers from aromatic acetylenes. Polymer 2006, 47, 4867-4892.

2. Yashima, E.; Maeda, K.; Iida, H.; Furusho, Y.; Nagai, K. Helical polymers: Synthesis, structures, and functions. Chem. Rev. 2009, 109, 6102-6211.

3. Ito, S.; Nozaki, K. Asymmetric polymerization. In Catalytic Asymmetric Synthesis, 3rd ed.; Ojima, I., Ed.; Wiley: Hoboken, NJ, USA, 2010; pp. 931-985.

4. Aoki, T.; Kaneko, T.; Maruyama, N.; Sumi, A.; Takahashi, M.; Sato, T.; Teraguchi, M. Helix-sense-selective polymerization of achiral phenylacetylene having two hydroxy groups using a chiral catalytic system. J. Am. Chem. Soc. 2003, 125, 6346-6347.

5. Sato, T.; Aoki, T.; Teraguchi, M.; Kaneko, T.; Kim, S.Y. Role of chiral amines in helix-senseselective polymerization of a phenylacetylene using chiral amines as cocatalysts. Polymer 2004, $45,8109-8114$.

6. Hadano, S.; Teraguchi, M.; Kaneko, T.; Aoki, T. Enantioselective permeability through membranes from a poly(substituted phenylacetylene) having a chiral helical backbone and achiral bidentate ligands as pendant groups. Chem. Lett. 2007, 36, 220-221.

7. Katagiri, H.; Kaneko, T.; Teraguchi, M.; Aoki, T. Copper(I) iodide accelerates catalytic activation in rhodium complex-catalyzed helix-sense-selective polymerization of achiral phenylacetylene monomers. Chem. Lett. 2008, 37, 390-391.

8. Umeda, Y.; Kaneko, T.; Teraguchi, M.; Aoki, T. Helix-sense-selective polymerization of a phenylacetylene bearing an achiral and bulky galvinoxyl moiety. Chem. Lett. 2005, 34, 854-855.

9. Kaneko, T.; Umeda, Y.; Yamamoto, T.; Teraguchi, M.; Aoki, T. Assignment of helical sense for poly(phenylacetylene) bearing achiral galvinoxyl chromophore synthesized by helix-senseselective polymerization. Macromolecules 2005, 38, 9420-9426.

10. Kaneko, T.; Umeda, Y.; Jia, H.; Hadano, S.; Teraguchi, M.; Aoki, T. Helix-sense tunability induced by achiral diene ligands in the chiral catalytic system for the helix-sense-selective polymerization of achiral and bulky phenylacetylene monomers. Macromolecules 2007, 40, 7098-7102.

11. Hadano, S.; Teraguchi, M.; Kaneko, T.; Aoki, T. Enantioselective permeability through membranes from a poly(substituted phenylacetylene) having a chiral helical backbone and achiral bidentate ligands as pendant groups. Chem. Lett. 2007, 36, 220-221. 
12. Hadano, S.; Kishimoto, T.; Hattori, T.; Tanioka, D.; Teraguchi, M.; Aoki, T.; Kaneko, T.; Namikoshi, T.; Marwanta, E.; Helix-sense-selective polymerization of achiral bis(hydroxylmethyl)phenylacetylenes having an alkyl group of different lengths. Macromol. Chem. Phys. 2009, 210, 717-727.

13. Jia, H.; Hadano, S.; Teraguchi, M.; Aoki, T.; Abe, Y.; Kaneko, T.; Namikoshi, T.; Marwanta, E. Two modes of asymmetric polymerization of phenylacetylene having a L-valinol residue and two hydroxy groups. Macromolecules 2009, 42, 17-19.

14. Liu, L.; Zang, Y.; Hadano, S.; Aoki, T.; Teraguchi, M.; Kaneko, T.; Namikoshi, T. New achiral phenylacetylene monomers having an oligosiloxanyl group most suitable for helix-sense-selective polymerization and for obtaining good optical resolution membrane materials. Macromolecules 2010, 43, 9268-9276.

15. Liu, L.; Oniyama, Y.; Zang, Y.; Hadano, S.; Aoki, T.; Teraguchi, M.; Kaneko, T.; Namikoshi, T.; Marwanta, E. Synthesis and helix-sense-selective polymerization of a novel phenylacetylene having a trisiloxanyl group and two hydroxyl groups and enantioselective permeability of the resulting chiral polymeric membrane: Effect of the trisiloxanyl group on the polymerization and enantioselective permeability. Polymer (Comm.) 2010, 51, 2460-2464.

16. Nolte, R.J.M.; Van Beijnen, A.J.M.; Drenth, W. Chirality in polyisocyanides. J. Am. Chem. Soc. 1974, 96, 5932-5933.

17. Okamoto, Y.; Suzuki, K.; Ohta, K.; Hatada, K.; Yuki, H. Optically active poly(triphenylmethyl methacrylate) with one-handed helical conformation. J. Am. Chem. Soc. 1979, 101, 4763-4765.

18. Nakano, T.; Okamoto, Y.; Hatada, K. Asymmetric polymerization of triphenylmethyl methacrylate leading to a one-handed helical polymer: Mechanism of polymerization. J. Am. Chem. Soc. 1992, 114, 1318-1329.

19. Nakano, T.; Nakagawa, O.; Tsuji, M.; Tanikawa, M.; Yade, T.; Okamoto, Y. Poly(2,7-di- $n$ pentyldibenzofulvene) showing chiroptical properties in the solid state based purely on a chiral conformation. Chem. Commun. 2004, 144-145.

20. Su, S.J.; Kuramoto, N. In situ synthesis of optically active poly(o-ethoxyzniline) in organic media and its chiroptical properties. Chem. Mater. 2001, 13, 4787-4793.

21. Oishi, T.; Kagawa, K.; Nagata, H. Synthesis and polymerization of maleimide containing an L-menthoxy group. Polymer 1997, 38, 1461-1469.

22. Nakano, T.; Tamada, D.; Miyazaki, J.; Kakiuchi, K.; Okamoto, Y. Asymmetric radical polymerization of maleimides using a chiral cobalt(II) complex. Macromolecules 2000, 33, 1489-1491.

23. Sakaguchi, T.; Kwak, G.; Masuda, T. Synthesis of poly(1- $\beta$-naphthyl-2-phenylacetylene) membranes through desilylation and their properties. Polymer 2002, 43, 3937-3942.

24. Wulff, G. Main-chain chirality and optical activity in polymers consisting of C-C chains. Angew. Chem. Int. Ed. Engl. 1989, 28, 21-37.

25. Wulff, G.; Dhal, P.K. Template monomer control of the chirality induction in the polymer backbone during asymmetric vinyl polymerization. Macromolecules 1990, 23, 4525-4527.

26. Wulff, G.; Schmidt, H.; Witt, H.; Zentel, R. Cooperativity and transfer of chirality in liquidcrystalline polymers. Angew. Chem. Int. Ed. Engl. 1994, 33, 188-191. 
27. Kakuchi, T.; Narumi, A.; Kaga, H.; Ishibashi, T.; Obata, M.; Yokota, K. Chirality induction in cyclocopolymerization. 13. Structural effect of 1,3-diol as chiral templates in the cyclocopolymerization of bis(4-vinylbenzoate)s with styrene. Macromolecules 2000, 33, 3964-3969.

28. Kakuchi, T.; Narumi, A.; Kaga, H.; Yamauchi, Y.; Obata, M.; Uesaka, T.; Yokota, K. Chirality induction in cyclocopolymerization. 14. Template effect of 1,2-cycloalkanediol in the cyclocopolymerization of bis(4-vinylbenzoate)s with styrene. Macromolecules 2001, 34, 38-43.

29. Yu, Z.; Wan, X.; Zhang, H.; Chen, X.; Zhou, Q. A free radical initiated optically active vinyl polymer with memory of chirality after removal of the inducing stereogenic center. Chem. Commun. 2003, 974-975.

30. Abe, Y.; Aoki, T.; Jia, H.; Hadano, S.; Namikoshi, T.; Kakihana, Y.; Liu, L.; Zang, Y.; Teraguchi, M.; Kaneko, T. Polymer 2012, submitted.

31. Amabilino, D.B.; Ramos, E.; Serrano, J.L.; Sierra, T.; Veciana, J. Long-range chiral induction in chemical systems with helical organization. Promesogenic monomers in the formation of poly(isocyanide)s and in the organization of liquid crystals. J. Am. Chem. Soc. 1998, 120, 9126-9134.

32. In the case of poly(3) without the spacer, it was insoluble.

33. Abe, Y.; Aoki, T.; Jia, H.; Hadano, S.; Namikoshi, T.; Kakihana, Y.; Liu, L.; Zang, Y.; Teraguchi, M.; Kaneko, T. Chem. Lett. 2012, in press.

34. The sign of the CD signals for poly(re-1) was opposite to those for poly(1) and poly(de-1). The reason is not clear at present but since they are not mirror images each other, it did not show inversion of the helical sense.

Sample Availability: Samples of the compounds 1a, 1e and $\mathbf{1 f}$ are available from the authors.

(C) 2012 by the authors; licensee MDPI, Basel, Switzerland. This article is an open access article distributed under the terms and conditions of the Creative Commons Attribution license (http://creativecommons.org/licenses/by/3.0/). 